\title{
Comparison of management strategies for the charging schedule and all-electric operation of a plug-in hybrid-electric bi-articulated bus fleet
}

\author{
Dennis Dreier $^{1}$ (D) $\cdot$ Björn Rudin ${ }^{2}$ (D) Mark Howells ${ }^{3,4}$
}

Accepted: 19 January 2020 / Published online: 26 May 2020

(c) The Author(s) 2020

\begin{abstract}
This study developed a real-time optimisation (RTO) model that uses real-world bus operation data, i.e. route-specific and time-specific driving cycles. Potentials for energy savings and all-electric operation were estimated for a plug-in hybridelectric bi-articulated bus fleet (PLUG scenario) that can be managed according to different management strategies. Five strategies, A to E, were simulated that manage the charging schedule and all-electric operation with different priorities: PLUGA, prioritise buses for charging by arrival times at the charging station (first come, first served); PLUG-B, prioritise buses for charging by energy intensities of the bus routes; PLUG-C, minimise the total energy use of the bus fleet; PLUG-D, maximise the total all-electric time of the bus fleet; and PLUG-E, maximise the total all-electric distance of the bus fleet. For comparison, a business-as-usual (BAU) scenario with conventional buses and another scenario with hybrid-electric buses (HYB) were simulated. Two weeks of real-world bus operation data from the city of Curitiba in Brazil were used as input data. The study finds that total energy savings of $17 \%$ and $27 \%$ in the HYB and PLUG scenarios can be achieved compared to the BAU scenario, respectively. Meanwhile, the average shares of the total all-electric time (TAET) and total all-electric distance (TAED) to the total bus fleet operation amount to $20 \%$ and $14 \%$ in the HYB scenario. Furthermore, both TAET and TAED in the PLUG scenario depend strongly on the chosen strategy amounting to ranges of $21-64 \%$ and $17-61 \%$, respectively. Simultaneous maxima were found for strategy D.
\end{abstract}

Keywords Bus · Driving cycle $\cdot$ Energy $\cdot$ Operations research $\cdot$ Optimisation · Simulation

\footnotetext{
Electronic supplementary material The online version of this article (https://doi.org/10.1007/s 1246
} 9-020-00227-z) contains supplementary material, which is available to authorized users.

Extended author information available on the last page of the article 


\begin{tabular}{ll} 
Abbreviations \\
ANOVA & Analysis of variance \\
B100 & Biodiesel 100\% \\
B7 & Fuel blend with 7\% biodiesel and 93\% petroleum diesel \\
BAU & Business-as-usual scenario \\
BRT & Bus rapid transit \\
CD-mode & Charge-depleting mode \\
CS-mode & Charge-sustaining mode \\
gCO 2 e & Grams of CO equivalent \\
GPS & Global Positioning System \\
GVW & Permitted gross vehicle weight \\
HYB & Hybrid-electric scenario \\
Kurt. & Kurtosis \\
LHV & Lower heating value \\
N & Number of measurements \\
p & p-value \\
PLUG & Plug-in hybrid-electric scenario \\
Q1 & First quartile (25\%) \\
Q3 & Third quartile (75\%) \\
RTO & Real-time optimisation \\
SD & Sample standard deviation \\
Skew. & Skewness \\
SOC & State-of-charge \\
SOChigh & Upper bound of the state-of-charge \\
SOClow & Lower bound of the state-of-charge \\
TAED & Total all-electric distance of the bus fleet \\
TAET & Total all-electric time of the bus fleet \\
TES & Total energy savings of the bus fleet \\
TEU & Total energy use of the bus fleet \\
& \\
\hline &
\end{tabular}

\section{Introduction}

The Paris Agreement of the Conference of Parties (COP) 21 reinforced the aim to limit global warming to a global mean temperature rise of well below $2{ }^{\circ} \mathrm{C}$ compared to pre-industrial levels (UNFCCC 2015). For the achievement of this target, anthropogenic greenhouse gas (GHG) emissions must be reduced. However, cities consume $60-80 \%$ of the total final energy and emit approximately the same share of total GHG emissions (EC 2018). The transport sector, in particular, depends strongly on petroleum-derived fuels with a consumption of $65 \%$ of the yearly oil products (IEA 2016). Progressive urbanisation (United Nations 2014) will presumably lead to an increasing demand for urban mobility and consequently, cities must act to considerably reduce fossil energy use and GHG emissions from urban transportation. Moreover, the issue of urban noise emissions has got more attention lately and is now considered as a severe health threat for humans (EC 2017; WHO 2012). 
Under several initiatives, e.g. the C40 network (C40 2018), the Covenant of Mayors for Climate \& Energy (Covenant of Mayors 2018) or the URBACT programme (URBACT 2018), cities have started to renew their public bus transport systems by introducing plug-in hybrid-electric and/or battery-electric buses. Conventional diesel buses can drive more than $300 \mathrm{~km}$ without any refuelling (Mahmoud et al. 2016). However, plug-in hybrid-electric and/or battery-electric buses can only use all-electric drive for 7-200 km with one battery charge (Mahmoud et al. 2016; Stokes and Poger 2013; Volvo Group UK 2017). The rather wide range of 7-200 km is mainly explained by different nominal capacities of on-board batteries deployed in those types of buses. This raises the issue of range anxiety for bus operators, which implies potential operation stops when the on-board battery is depleted. In contrast, plug-in hybrid-electric buses can overcome the range anxiety issue by using an internal combustion engine as range extender. For this reason, plug-in hybrid-electric buses have been considered as a transition technology towards full-electrified bus transport systems. Yet, the achievable energy and emission reductions (Dreier et al. 2018, 2019) as well as silent operation (Borén et al. 2016) last as long as this type of bus uses its electric motor for propulsion instead of combusting liquid fuel such as diesel in the internal combustion engine. Therefore, a large share of all-electric operation is desirable to benefit the most from the electrification.

Certainly, one solution is the deployment of a larger battery to increase the allelectric range. However, considering that the battery represents $23 \%$ of the capital costs of an electric bus (Ding et al. 2015; Olsson et al. 2016), this would also imply a considerable increase in costs. Another solution is a more wide-spread installation of charging infrastructure to enable opportunity charging, i.e., the battery is occasionally recharged during operation. Opportunity charging usually takes place at bus stations equipped with charging stations, since here, the dwell time for passengers to get on and off from the bus can be simultaneously used for recharging the battery. In that case, the redesign of existing bus transport systems is required to prepare them for electrification and charging to ensure an unbroken service. Redesign is not only limited to charging infrastructure per se, but also the bus fleet's management concerning the charging schedule, i.e., when and how long to charge buses. Moreover, the all-electric operation could be planned, i.e., when and how long to use the electric motor instead of the internal combustion engine.

This paper contributes to the operational optimisation of electrified bus transport systems. A real-time optimisation (RTO) model is developed and tested to manage plug-in hybrid-electric bus fleets. The goal is to maximise electrification benefits while ensuring punctuality in a given setting. Five different management strategies are analysed regarding total energy savings (TES) and all-electric operation. The latter is measured in terms of total all-electric time (TAET) and total all-electric distance (TAED) of the bus fleet. A case study is used to demonstrate the real-time optimisation model approach using real-world bus operation data. This leads to the overarching research question in this study, and is formulated as follows: What are the potentials for total energy savings and all-electric operation for a plug-in hybrid-electric bus fleet operated according to selected management strategies?

The remaining paper is organised as follows. The innovation of this research is stated by first reviewing the existing literature and then, the methodological 
approach and the addition to knowledge are presented. After this, the conceptual framework of the real-time optimisation model is presented including its algebraic formulation, energy use estimation method, a description of computational challenges and a brief summary of the code implementation used in this study. Next, the case study is described including the system boundary, scenarios, management strategies and input data, validation of the energy use estimation method and a statistical analysis of bus routes. Then, the findings for the total energy savings and total all-electric operation of the bus fleet are presented, discussed, and compared to each other. Finally, conclusions are given and some indications for future work. The abbreviations section above contains a list of abbreviations. The supplementary material provides two files: (1) a word file containing the description of the data preparation process; (2) an excel file containing detailed statistics and results of the case study.

\section{Innovation of this research}

\subsection{Literature review}

A considerable amount of research has been carried out to facilitate the understanding of potential transition processes from bus transport systems operating conventional buses to bus transport systems operating electrified bus fleets and charging infrastructure. Several methods, tools and algorithms have been developed for the (re-)design of transport systems. For example, Ranta et al. (2016) developed a suite of tools to design routes, simulate electric buses and analyse power requirements for chargers at charging stations. The design and dimensioning of charging infrastructure have been investigated to a large extent in the scientific literature. Some studies focused on the determination of locations for charging stations in public bus transport systems (e.g. He et al. 2018; Xylia et al. 2017). In addition to the locations, many studies also included the dimensioning of the capacity of batteries in electric buses, for example: Kunith et al. (2017) investigated the trade-off between the battery's capacity and required charging infrastructure under different infrastructure and operational conditions; Gao et al. (2017) found considerable cost savings if different sizes of batteries, together with battery switching practices, are applied while considering timetables and routes; Rogge et al. (2015) recommend to focus on the entire timetable of a bus fleet instead of individual trips; Liu and Song (2017) presented a tool for locating wireless charging stations and sizing of the battery; and Sebastiani et al. (2016) investigated the trade-off between the number of charging stations and charge time.

While much research has been carried out concerning physical charging infrastructure, the management of a bus fleet must be also considered. The possibility to use charging infrastructure must be given without compromising punctuality of the transport service. However, only a few studies focused on the charging schedule of buses. For example, while van Kooten Niekerk et al. (2017) analysed the bus fleet management for only one bus depot, other studies also included the operation on bus routes, such as Qin et al. (2016) who simulated fast charging strategies to reduce the charge demand of electric buses. Wang et al. (2017) focused, among other aspects, 
on the optimisation of the charging schedule for electric buses with the objective to minimise the annual total operating costs of the charging system. A limitation of the aforementioned studies is the lack of real-world data. Many of those studies were rather based on an idealised timetable schedule for charging that, however, neglects the potential occurrences of unexpected deviations, such as traffic flow changes and delays due to car accidents, etc.

A more flexible approach represents real-time optimisation. This has been only analysed to a limited extent for charging of plug-in hybrid-electric and/or electric buses though. The term real-time in the field of optimisation refers to the consideration of feedback and periodic repetition of the optimisation process. In this study, real-time optimisation terms the interference of an optimisation model into the current operation of a bus fleet. The real-time optimisation approach is a control technique that periodically (in this paper: a time interval of $180 \mathrm{~s}$ ) collects the operation data from the bus fleet; then the data is used to optimise the operation predicted for the time interval; and eventually, the results from the optimisation are sent as decision signals to the buses to control their charging schedule and/or all-electric operation.

Some research has been carried out in the area of real-time optimisation for buses in operation. For example, Yu et al. (2016a) used real-time optimisation to analyse one bus in detail concerning its on-board energy management system. Paul and Yamada (2014) focused on the charging schedule of electric buses on four bus routes in the case of Japan with the aim to maximise the total all-electric distance driven by the whole electric bus fleet. However, it should be noted that a maximisation of the allelectric distance of plug-in hybrid-electric and/or electric bus fleet neglects the consideration that energy use depends not only on the type of bus and distance, but also on route-specific and time-specific driving cycles (Dreier et al. 2018; Rahman et al. 2018; Suzdaleva and Nagy 2018; Tao et al. 2018). Consequently, the objective of maximising the all-electric distance of a bus fleet does not necessarily imply to use the full potential for both total energy savings and all-electric operation. Furthermore, Paul and Yamada (2014) only considered an average value for the energy use of the electric buses, i.e. no real-world driving cycles. This simplification applies to many other scientific studies, too. However, the use of local real-world driving cycles in optimisation models is important, since they can differ strongly from standardised driving cycles or from assuming an average value for energy use of buses. As a result, the real-world heterogeneity in transport systems is neglected (Millo et al. 2014; Wang et al. 2015; Xu et al. 2015; Yay et al. 2016; Zhang et al. 2014).

In summary, much research has been carried out for designing bus transport systems. This is especially the case for the determination of optimal locations for charging stations. However, the literature typically does not report studies that use real-time optimisation for the charging schedule and/or all-electric operation. Nor do they report multiple relevant goals, such as: minimising total energy use and maximising total all-electric operation. Moreover, many of the reported models assume average values for the energy use of buses. Those can considerably differ from realworld operations and hence, neglect heterogeneity in an actual bus transport system. Finally, management strategies based on a fixed timetable for the bus fleet are static and, thus, do not automatically include deviations from the expected operations of buses. 


\subsection{Contributions}

This paper conceptualises and implements a real-time optimisation model for managing the charging schedule and all-electric operation of a plug-in hybrid-electric bus fleet. In contrast to many other studies, real-world bus operation data was used to estimate the individual energy use rates of buses in a bus fleet. In this way, some level of heterogeneity of route-specific and time-specific driving cycles was captured. This was then integrated into the optimisation model. The joint usage of the real-time optimisation approach and real-world data potentially allows a more dynamic and realistic data-driven decision-making process in this study compared to the other aforementioned studies.

The real-time optimisation model was used to estimate and compare the total energy savings and the total all-electric operation for a plug-in hybrid-electric bus fleet. Five different management strategies (A-E) for the charging schedule and/or all-electric operation are simulated and compared for the case of a plug-in hybridelectric bus fleet (PLUG scenario): PLUG-A, prioritise buses for charging by arrival times at the charging station (first come, first served); PLUG-B, prioritise buses for charging by energy intensities of the bus routes; PLUG-C, minimise the total energy use of the bus fleet; PLUG-D, maximise the total all-electric time of the bus fleet; and PLUG-E, maximise the total all-electric distance of the bus fleet. Note: The comparison of strategy $\mathrm{E}$ to the remaining four strategies A, B, C and D is a distinct difference to the management strategy analysed in the study by Paul and Yamada (2014) who also aimed at maximising the total all-electric distance of a bus fleet like strategy E. Moreover, their study considered the case of battery-electric buses, whereas our study analyses plug-in hybrid-electric buses.

A case study is used to demonstrate the real-time-optimisation model and compare the five strategies. The bus operation datasets originate from the city of Curitiba in Southern Brazil. At present, conventional bi-articulated buses are predominantly operated in Curitiba's bus rapid transit (BRT) system. This applies to many other cities, too. Noteworthy, Curitiba committed to introduce low emissions buses in the scope of a C40 network initiative (C40 2015). One plug-in hybrid-electric bus and one battery-electric bus were tested during 2015-2017 (URBS 2015; Volvo Bus Corporation 2016a). As in Curitiba, many other C40 and non-C40 cities have started to electrify their bus transport system globally, e.g. see the cities cited in ZeEUS Project (2016). Therefore, it is also of interest to quantify how the degree of electrification of the bus fleet influences both energy savings and all-electric operation of the system. Hence, a business-as-usual scenario (BAU scenario) with conventional bi-articulated buses and a hybrid-electric scenario (HYB scenario) with hybrid-electric bi-articulated buses were modelled to complement the PLUG scenario. These were simulated to estimate the change in energy savings and all-electric operation among the different degrees of electrification (BAU, HYB, PLUG). This comparison for the case of a BRT system may be of interest to many cities in developing countries. The BRT concept has been frequently implemented in those cities due to significantly lower capital costs compared to metro-systems (Wright and Hook 2007), while having a similar passenger carrying capacity and convenience (Hensher and Golob 2008; Hensher and Mulley 2015; Zhang 2009); see, e.g., the cities cited in 
Hensher and Li (2012a), (b), Heres et al. (2014). Thus, the real-time optimisation model and findings of this study may be of interest to a wider audience involved in city and transport planning aiming at urban sustainability, energy security and climate mitigation.

While finding the answer to the above research question What are the potentials for total energy savings and all-electric operation for a plug-in hybrid-electric bus fleet operated according to selected management strategies?, the following methodological advances and contributions to knowledge are made and summarised below:

(1) Comparison of five management strategies for the PLUG scenario that focus on multiple objectives including: energy savings and all-electric operation for the case of plug-in hybrid-electric bi-articulated buses.

(2) Comparison of three electrification scenarios (BAU, HYB, PLUG) for the case of bi-articulated buses in a BRT system.

(3) Development of a flexible and scalable real-time optimisation model.

(4) Integration of real-world driving cycles into the optimisation model for more dynamic and realistic data-driven decision-making.

(5) The C40 network has one member (Curitiba) now with a case study to demonstrate the real-time optimisation approach and to derive insights and recommendations for other cities having a similar status of electrification in their bus transport systems.

\section{Development of the real-time optimisation model}

The consideration of feedback and periodic repetition of the optimisation as in the real-time optimisation model requires periodic exchange of data. Related to this is the concept of Internet-of-Things (IoT) that has been popularised for the last years. IoT refers to connectivity of objects to the internet to exchange data. In the specific case of a bus transport system, the objects are buses, charging stations, and an online platform comprising a data transmitter, data receiver, data warehouse, software to process and analyse data, and to execute the code of the implemented real-time optimisation model. The conceptual framework of interaction between IoT-platform and a simplified bus transport system with charging stations at bus stations is illustrated in Fig. 1. The operation data from the buses is received by the IoT-platform, processed and then stored in a data warehouse. The data is retrieved from the data warehouse for a statistical analysis. Those results are used as input data in the optimisation model then. Next, the optimisation model is initialised and solved. The outputs are the decisions for the management of both charging schedule and/or allelectric operation of the buses. Those are received by the buses that operate accordingly. This is the basic concept of this type of control system. Next, the problem and necessity of this framework are further elaborated.

The management of the charging schedule increases in complexity with an increasing number of plug-in hybrid-electric and/or electric buses in a bus transport system. Time intervals for the charging schedule of buses can overlap. Or, more than one bus might simultaneously arrive at the same charging station and must be 


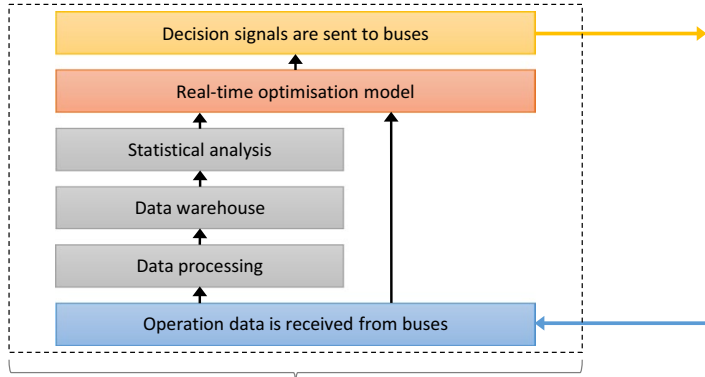

IOT-platform with RTO-model

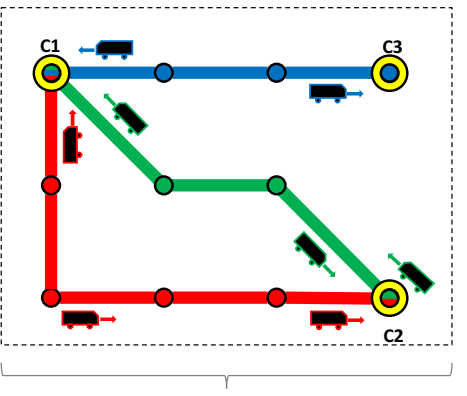

Bus transport system

Fig. 1 Conceptual framework of the interactions between an Internet-of-Things (IoT)-platform using a real-time optimisation (RTO) model and a simplified bus transport system with red, blue and green bus routes; circles: bus stations; and $\mathrm{C} 1 / 2 / 3$ : charging stations

charged; see, e.g., the situations at charging stations $\mathrm{C} 1$ and $\mathrm{C} 2$ in Fig. 1. In either case, a decision must be made in which order and how long each bus should be charged. This situation can be potentially caused if too few charging stations are in place, too many plug-in hybrid-electric and/or electric buses are operated, or timetables of the buses coincide. Without any management solution, this situation can potentially lead to delays in the timetable or partial gridlocks in a bus transport system. Consequently, the problem of managing the charging schedule of a bus fleet must be solved to avoid operational issues.

The real-time optimisation model finds a solution to the problem by making decisions about the order and duration for charging each bus. Meanwhile, it can consider both historical and present bus operation data, and based on this, it can determine a management solution for the near future that also aims to increase particular benefits available from electrification of a bus transport system, e.g. energy savings and all-electric operation. The latter is quantified in terms of total all-electric operation time and total all-electric operation distance. Five management strategies concerning charging schedule and/or all-electric operation are simulated and compared for the PLUG scenario:

(A) Prioritise buses for charging by arrival times at the charging station (first come, first served)

(B) Prioritise buses for charging by energy intensities of the bus routes

(C) Minimise the total energy use of the bus fleet

(D) Maximise the total all-electric time of the bus fleet

(E) Maximise the total all-electric distance of the bus fleet

Strategy A does not pose any potential for optimisation of the charging schedule due to the fixed order set according to the arrival times of buses at a bus station where a charging station is placed. A bus that arrives first at a bus station having a charging station, is charged until it leaves the charging station again. The charging station is available for the next bus then. Since many cities only operate a few plug-in hybrid-electric and/or electric buses, strategy $\mathrm{A}$ is quite commonly used at present. However, there 
might be potential for improvement, which is assessed considering also the strategies $\mathrm{B}, \mathrm{C}, \mathrm{D}$ and $\mathrm{E}$. The use of those strategies requires some additional information about historical and present bus operations, such as information on the energy intensities of the bus routes (strategy B), or information on the current state-of-charge (SOC) in the battery and expected (near future) energy use over the time interval considered in the optimisation (strategies C, D and E). Note: SOC states the level of available electricity in the battery compared to its nominal capacity, i.e. $0 \%$ : empty; $100 \%$ : full. The SOC represents the analogue to the fuel gauge in a fuel tank as in the case of conventional buses.

\subsection{Computational challenges}

The actual implementation of the IoT-platform and real-time optimisation model raises computational challenges concerning data collection from the buses, data storage, data processing, the optimisation process as well as when sending the control signals to the buses. Thus, the computational challenges are directly linked to the components as previously shown in Fig. 1. New buses are usually equipped with telematics systems. Such a system allows to communicate remotely between the IT system of the bus and control centre of the bus operator company (Volvo Bus Corporation 2011). Taking this case, the next step would be to implement a computational application at the control centre. The design of such an application requires a flexible approach that ensures scalability in the future. A common solution is the use of cloud computers/servers to run computer applications. A cloud server is a virtual server that is not locally installed in form of a physical device where the computer application is used, but rather a server that can be located anywhere in the world. If more computational resources were needed due to an increasing number of buses in a bus fleet in the future, the cloud system could be extended by adding more servers to provide more computational power to process the increased data volume. Furthermore, concerning the real-time optimisation model and its optimisation algorithm, a computer cluster could be used to share the task among various computers. In this way, the potentially increased computational demand could still be met. Consequently, a larger bus fleet could be managed while using the same optimisation approach, such as the model presented in this study. There exists a range of commercially available cloud computing solutions as described in the review article by Drake (2018).

As our study intends to demonstrate the application of the real-time optimisation model approach, a rather small bus fleet was considered that only operates on four bus routes. The case is presented in Sect. 4. Therefore, the computational challenges were rather small in this case study. This allowed to run the real-time optimisation model on an ordinary laptop using Windows 10 (64-bit) and having an Intel ${ }^{\circledR}$ Core $^{\mathrm{TM}}$ i7-4600U CPU @ $2.10 \mathrm{GHz} 2.70 \mathrm{GHz}, 16$ GB working memory (RAM) and a 512 GB SSD.

\subsection{Algebraic formulation of the optimisation model}

The real-time optimisation model is used in periodic repetitions to optimise the charging schedule of buses: the decision variable is ChargingSlot $_{t, b, s, c}$. 
Meanwhile, the all-electric operation is also optimised, i.e., during which time steps a bus shall use all-electric drive: the decision variable is AllElectricDrive ${ }_{t, b}$. Thus, one bus operation day is divided into several discrete time intervals. In the following, the algebraic formulation of the optimisation model is presented as it is formulated and solved at one time point $t_{1}$ of the periodic repetitions over one time interval $t_{1}<t \leq t_{2}$ until the next repetition starts at $t_{2}$, i.e. a constrained steady-state mathematical optimisation problem. This algorithmic paradigm of finding at a time point $t_{1}$ an optimum over the time interval $\left(t_{1}<t \leq t_{2}\right)$ until the time point $t_{2}$ is a greedy algorithm, i.e., it determines succeeding discrete local optima for each discrete time interval over the operation day rather than determining one global optimum for the whole operation day. In other words, it determines the best solution for the present problem (i.e. current time interval) without any consideration of the consequences in the future (i.e. subsequent time intervals).

At the time point $t_{1}$, the optimisation model is initialised according to the set objective function considering either strategy A, B, C, D or E; the IoT-platform retrieves all information from the bus fleet and data warehouse; the input datasets are provided to the real-time optimisation model; and the optimisation model is solved. Depending on the strategy, one or two output/s from the solution of the optimisation model is/are needed to control the bus fleet. Strategies A and B only use one output which are the values of the variable ChargingSlot $_{t, b, s, c}$ for managing the charging schedule of each bus in the bus fleet. This is a binary variable which takes the value 1 for charging, and 0 for no charging. Moreover, all-electric operation is not optimised for those two strategies and buses always use all-electric drive when enough electricity is available in their batteries. In addition, strategies C, D and E optimise the values of variable AllElectricDrive ${ }_{t, b}$ for managing the all-electric operation of each bus in the bus fleet. This is a binary variable which takes the value 1 for all-electric drive, and 0 for no allelectric drive implying propulsion with the internal combustion engine.

The algebraic formulation of the optimisation model is written in plain English to ease readability. The model is formulated as mixed-binary linear programming problem considering operational and technical constraints. For an overview of the nomenclature and symbols for both elements and datasets see Box 1, and for variables, parameters and units see Table 1. Variables are written in italics and parameters in bold italics.

Box 1. Nomenclature and symbols for datasets in the optimisation model and energy use estimation method.

$\begin{array}{llll}b \in B & \text { Set of buses } & t \in T & \text { Set of discrete time steps } \\ f \in F & \text { Set of fuels other than electricity } & s \in S & \text { Set of bus stations } \\ c \in C & \text { Set of charging stations } & r \in R & \text { Set of routes }\end{array}$




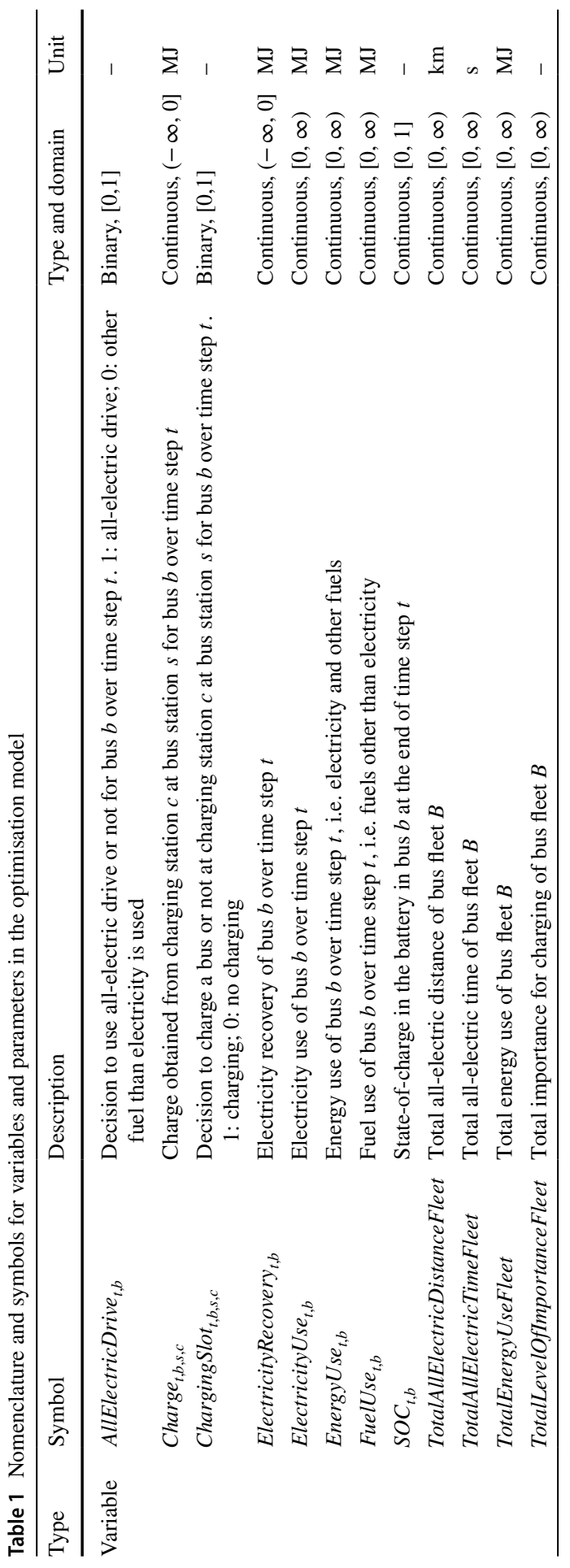




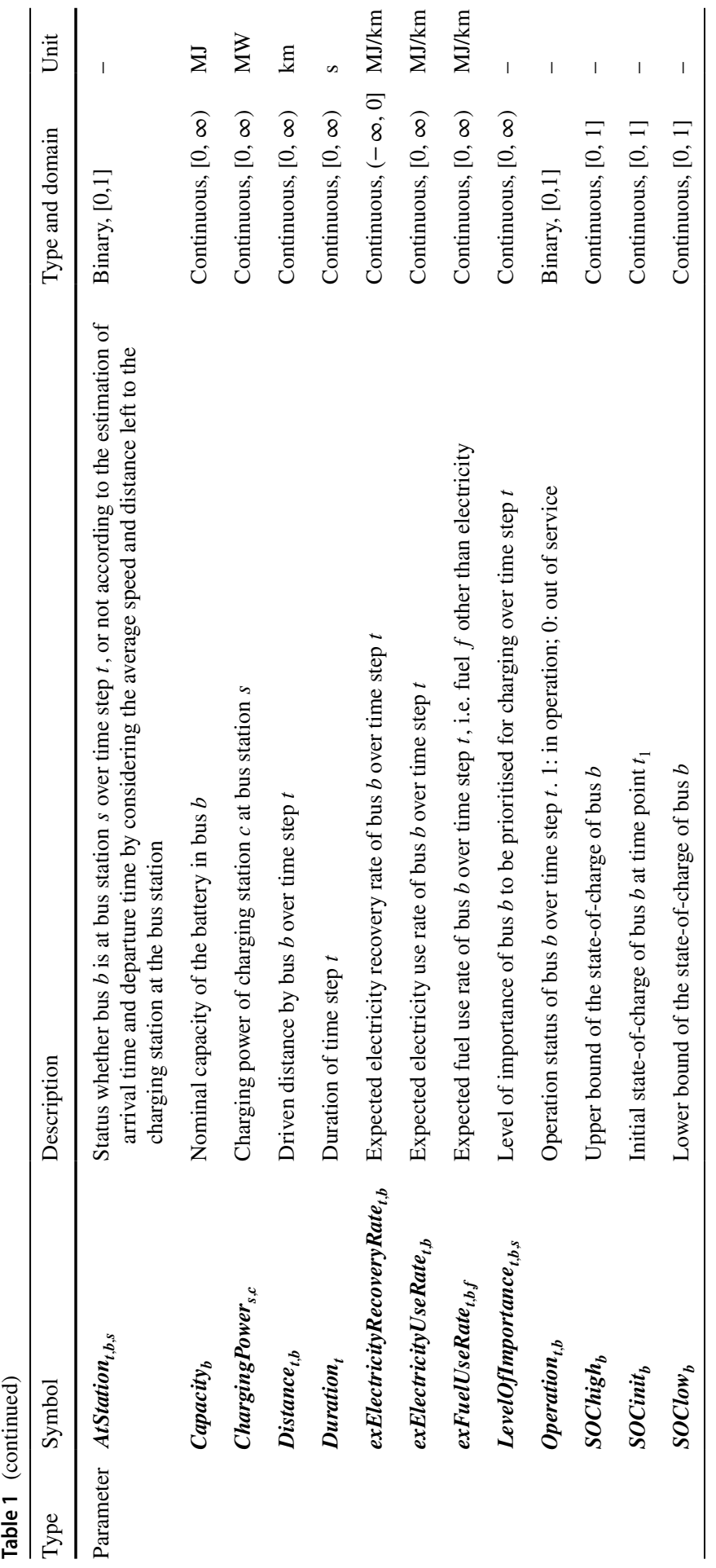




\subsubsection{Strategies A/B}

Strategies A and B prioritise buses for charging according to either their arrival times at the charging station (strategy A) or energy intensities of their bus routes (strategy B). The formulation of the optimisation model is the same for both strategies. A logic variable TotalLevelOfImportanceFleet is introduced that is maximised in the objective function (1). Each bus gets a logic parameter LevelOfImportance $\boldsymbol{t}_{t, \boldsymbol{b}, \boldsymbol{s}}$ which value is according to the respective level of importance of a bus. This defines a strict order and duration for the charging for each bus. Importantly, the numeric value of LevelOfImportance $_{t, b, s}$ must be always chosen large enough for a bus having a higher level of importance than for a bus with a lower level of importance to ensure no interruption of the charging process of the former by the latter. The difference between strategies A and B is only that the LevelOfImportance ${ }_{t, b, s}$ is determined by the arrival time in the case of strategy A, or determined by the energy intensities of the bus routes. The latter is calculated through a statistical analysis of historical bus operation data (Sect. 4.4). Logically, during a time step $t$, only one bus $b$ can be charged at a bus station $s$ at a charging station $c$ (3). Some buses start or end their operation during the considered time interval for the optimisation model in the bus operation dataset and, thus, a parameter is added to describe those cases, i.e., Operation $\boldsymbol{t}_{\boldsymbol{t}, \boldsymbol{b}}$ is equal to 1 when a bus is in operation or 0 when a bus is out of service. Consequently, a bus must be in operation to be charged (4). Moreover, the bus must be located at a bus station where a charging station is implemented (5), i.e., AtStation $\boldsymbol{t}_{\boldsymbol{t}, \boldsymbol{b}, \boldsymbol{s}}$ is equal to 1 if the bus is at the bus station, else 0 .

$$
\text { Strategy A/B : maximiseTotalLevelOfImportanceFleet }
$$

$$
\begin{gathered}
\text { TotalLevelOfImportanceOfFleet }=\sum_{t, b, s, c} \text { ChargingSlot }_{t, b, s, c} \times \text { LevelOfImportance }_{t, \boldsymbol{b}, \boldsymbol{s}} \\
\sum_{b} \text { ChargingSlot }_{t, b, s, c} \leq 1
\end{gathered}
$$

$$
\begin{gathered}
\text { ChargingSlot }_{t, b, s, c} \leq \text { Operation }_{t, \boldsymbol{b}} \\
\text { ChargingSlot }_{t, b, s, c} \leq \text { AtStation }_{\boldsymbol{t}, \boldsymbol{b}, \boldsymbol{s}}
\end{gathered}
$$

Example calculation for the LevelOfImportance $_{t, b, s}$ : Let us consider the situation in which two buses approach a charging station. And, the first bus $b=1$ arrives before the second bus $b=2$, which implies the first bus shall be prioritised over the second bus according to strategy $\mathrm{A}$. The time interval in the optimisation model includes $180 \mathrm{~s}$, and each time step amounts to $10 \mathrm{~s}$, i.e. 18 time steps in total. Any arbitrary but fixed number can be chosen for the LevelOfImportance ${ }_{t, b, s}$ for each time step for the first bus $b=1$, for example 1. In the case of the second bus, the sum of all LevelOfImportance $_{t, b, s}$ must be smaller than the LevelOfImportance ${ }_{t, b, s}$ at any time step of the first bus, e.g., every LevelOfImportance ${ }_{t, b, s}$ for the second bus amounts 
to $1 /(18+1)$. This means that the sum over all 18 time steps, i.e. $18 \cdot 1 /(18+1)$, amounts to $18 / 19$ for the second bus, which is smaller than 1, i.e., the second bus will be never prioritised over the first bus in the optimisation model. This example demonstrates how the input data for the LevelOfImportance ${ }_{t, b, s}$ can be determined.

\subsubsection{Strategies C/D/E}

Strategies C, D and E are used to estimate potentials for the objective either to minimise the total energy use (strategy C) (6) or maximise the total all-electric operation over time (strategy D) (7) or the total all-electric operation over distance (strategy E) (8) of the bus fleet. The choice of which objective function to apply is done by excluding the respective other two objective functions from the implementation of the optimisation model. The remaining equations are the same for strategies $\mathrm{C}, \mathrm{D}$ and $\mathrm{E}$.

The total energy use of the bus fleet (TotalEnergyUseFleet) (9) accounts for each bus the fuel use for propulsion using an internal combustion engine $\left(\right.$ FuelUse $\left._{t, b}\right)$ (12), electricity use for all-electric drive using an electric motor (ElectricityUse $e_{t, b}$ ) (13) and electricity recovery from a regenerative braking system (ElectricityRecovery ${ }_{t, b}$ ) (14). Electricity recovery is accounted with a negative number, since energy is recovered and not used. Electricity $U_{s} e_{t, b}$ is calculated by the expected electricity use rate $\left(\right.$ exElectricityUseRate $\left._{t, \boldsymbol{b}}\right)$ times driven distance $\left(\right.$ Distance $\left._{t, \boldsymbol{b}}\right)$ times the binary variable AllElectricDrive ${ }_{t, b}$ that states whether all-electric drive is used or not. If AllElectricDrive ${ }_{t, b}$ equals 1, all-electric drive is used, which also implies that FuelUse $_{t, b}$ is not used, i.e. either electricity use (13) or fuel use (12). Moreover, both distance (10) and time (11) are accounted as all-electric operation in the case AllElectricDrive ${ }_{t, b}$ equals 1.

$$
\text { Strategy C : minimise TotalEnergyUseFleet }
$$

Strategy D : maximise TotalAllElectricTimeFleet

Strategy E : maximise TotalAllElectricDistanceFleet

TotalEnergyUseFleet $=\sum_{t, b}\left(\right.$ FuelUse $_{t, b}+$ ElectricityUse $_{t, b}+$ ElectricityRecovery $\left._{t, b}\right)$

TotalAllElectricDistanceFleet $=\sum_{t, b}$ Distance $_{t, b} \times$ AllElectricDrive $_{t, b}$

$$
\text { TotalAllElectricTimeFleet }=\sum_{t, b} \text { Duration }_{t} \times \text { AllElectricDrive }_{t, b}
$$

$$
\text { FuelUse }_{t, b}=\sum_{f} \text { exFuelUseRate }_{t, b, f} \times \text { Distance }_{t, b} \times\left(1-\text { AllElectricDrive }_{t, b}\right)
$$




$$
\text { ElectricityUse }_{t, b}=\text { exElectricityUseRate }_{t, b} \times \text { Distance }_{t, b} \times \text { AllElectricDrive }_{t, b}
$$

$$
\text { ElectricityRecovery }_{t, b}=\text { exElectricityRecoveryRate }_{t, b} \times \text { Distance }_{t, b}
$$

The decision whether all-electric drive can be used or not, i.e. the value for AllElectricDrive $_{t, b}$, is determined by (15)-(18). The dataset contains data points from the real-world bus operations and thus, it is a collection of discrete observations. The equation system is designed according to the requirement for AllElectricDrive $_{t, b}$ of a bus $b$ that its all-electric operation must last over the whole duration of a time step $t$. Whether to use all-electric drive or not depends on the available amount of electricity in the battery stated by the SOC of a bus $\left(S O C_{t, b}\right)$. It is calculated by the initial SOC $\left(\right.$ SOCinit $\boldsymbol{b}$ ) at time point $t_{1}$ of the considered time interval $t_{1}<t \leq t_{2}$ and the change of the amount of electricity in the battery $\sum_{t}(\ldots)$ related to its nominal capacity of the battery $\left(\right.$ Capacity $_{b}$ ) (15). Some constraints apply to $S O C_{t, b}$ and AllElectricDrive $e_{t, b}$. The $S O C_{t, b}$ is constrained by the upper bound of the SOC (SOChigh $\boldsymbol{b}_{\boldsymbol{b}}$ ) (16) and the lower bound of the SOC (SOClow $\boldsymbol{w}_{\boldsymbol{b}}$ ) (17). The consideration of both $\boldsymbol{S O C h i g h}_{\boldsymbol{b}}$ and $\boldsymbol{S O C l o w}_{\boldsymbol{b}}$ is important, because operations outside of this SOC window lead to increasing battery wear (Wikner and Thiringer 2018). Moreover, all-electric drive can be only used if the bus is actually in operation, i.e., Operation $_{t, b}$ is equal to 1 (18).

$$
\operatorname{SOC}_{t, b}=\text { SOCinit }_{b}-\sum_{t}\left(\text { ElectricityUse }_{t, b}+\text { ElectricityRecovery }_{t, b}+\sum_{t e r} \sum_{c s} \text { Charge }_{t, b, s, c}\right) / \text { Capacity }_{b}
$$

$$
\begin{gathered}
\text { SOC }_{t, b} \leq \text { SOChigh }_{\boldsymbol{b}} \\
\text { AllElectricDrive }_{t, b} \leq \operatorname{SOC}_{t, b} / \text { SOClow }_{\boldsymbol{b}} \\
\text { AllElectricDrive }_{t, b} \leq \text { Operation }_{t, \boldsymbol{b}}
\end{gathered}
$$

The amount of electricity, that is obtained from a charging station, is described in (19)-(22). The same constraints (3)-(5) as in strategies A and B also apply to strategies C, D and E (19)-(21), i.e., for charging a bus must be in operation and at a bus station having a charging station. The expected amount of electricity, that is charged to the battery of a bus, is calculated by Eq. (22). This equation implies that if a bus does not receive a charging slot at a charging station (ChargingSlot $t_{t, b, s, c}$ ), then ChargingSlot $_{t, b, s, c}$ is equal to 0 and thus, no charge is given to the battery of that bus.

$$
\begin{gathered}
\sum_{b} \text { ChargingSlot }_{t, b, s, c} \leq 1 \\
\text { ChargingSlot }_{t, b, s, c} \leq \text { Operation }_{t, \boldsymbol{b}}
\end{gathered}
$$




$$
\begin{gathered}
\text { ChargingSlot }_{t, b, s, c} \leq \text { AtStation }_{t, b, s} \\
\text { Charge }_{t, b, s, c}=\text { ChargingPower }_{s, c} \times \text { Duration }_{t} \times \text { ChargingSlot }_{t, b, s, c}
\end{gathered}
$$

The three parameters exElectricityUseRate ${ }_{t, b}$, exElectricityRecoveryRate ${ }_{t, b}$ and $\boldsymbol{e x F u e l U s e R a t e}_{t, \boldsymbol{b}, f}$ must be provided as input data to use strategies C, D and E. They represent the expected energy use and recovery for the buses over the time interval considered in the optimisation model. The study aims to estimate available potentials obtained by using strategies C, D and E. Moreover, historical bus operation data was used to simulate the case study. Thus, the expected energy use and recovery correspond to the actual values that could be calculated for each bus using the energy use estimation method formulated in the next section.

One remark regarding the computational complexity of the optimisation model: The more buses, routes, and charging stations are considered, the more complex becomes the optimisation problem. Common algorithms to solve linear optimisation models, such as the simplex method, usually increase polynomially in time with an increasing number of variables and constraints (Spielman and Teng 2004). Thus, the solving time of the model is expected to increase polynomially when using the same hardware and code implementation. However, it should be noted that both software and hardware should be scaled up in such a case to sustain a fast computation for the real-time optimisation approach, e.g., by splitting up the model into smaller models and use parallel computing on a computer cluster.

\subsection{Algebraic formulation of the energy use estimation method}

Different methods exist to estimate the energy use of road vehicles. Many of those require plenty of technical information such as: the brake-specific fuel consumption map of an internal combustion engine, operational efficiency map of an electric motor, and other performance characteristics of all powertrain components as well as their interplay. To limit data requirements and ensure the reproducibility of this study as well as ease an application of the real-time optimisation model with similar datasets in studies in the future, a simpler calculation method was selected. It is based on the instantaneous power of a vehicle. Through the integration of this method into the previously presented optimisation model, route-specific and timespecific driving cycles could be used to estimate individual energy use rates of buses. The combination of the optimisation model from the previous section and the energy use estimation method in this section is a distinct difference to many previous studies and overcomes the frequent limitation of considering an average value for the energy use of buses. For an overview of the nomenclature and symbols for both elements and datasets see again Box 1, and for variables, parameters and units see again Table 2. Variables are written in italics and parameters in bold italics.

In short, the electricity use rate (23) and fuel use rate (24) of a road vehicle depend on the instantaneous power requested by the driving cycle and the environment (25). Here, the use of powertrain efficiencies enables the creation of an analytical function to estimate both electricity use rate and fuel use rate. The instantaneous power is 


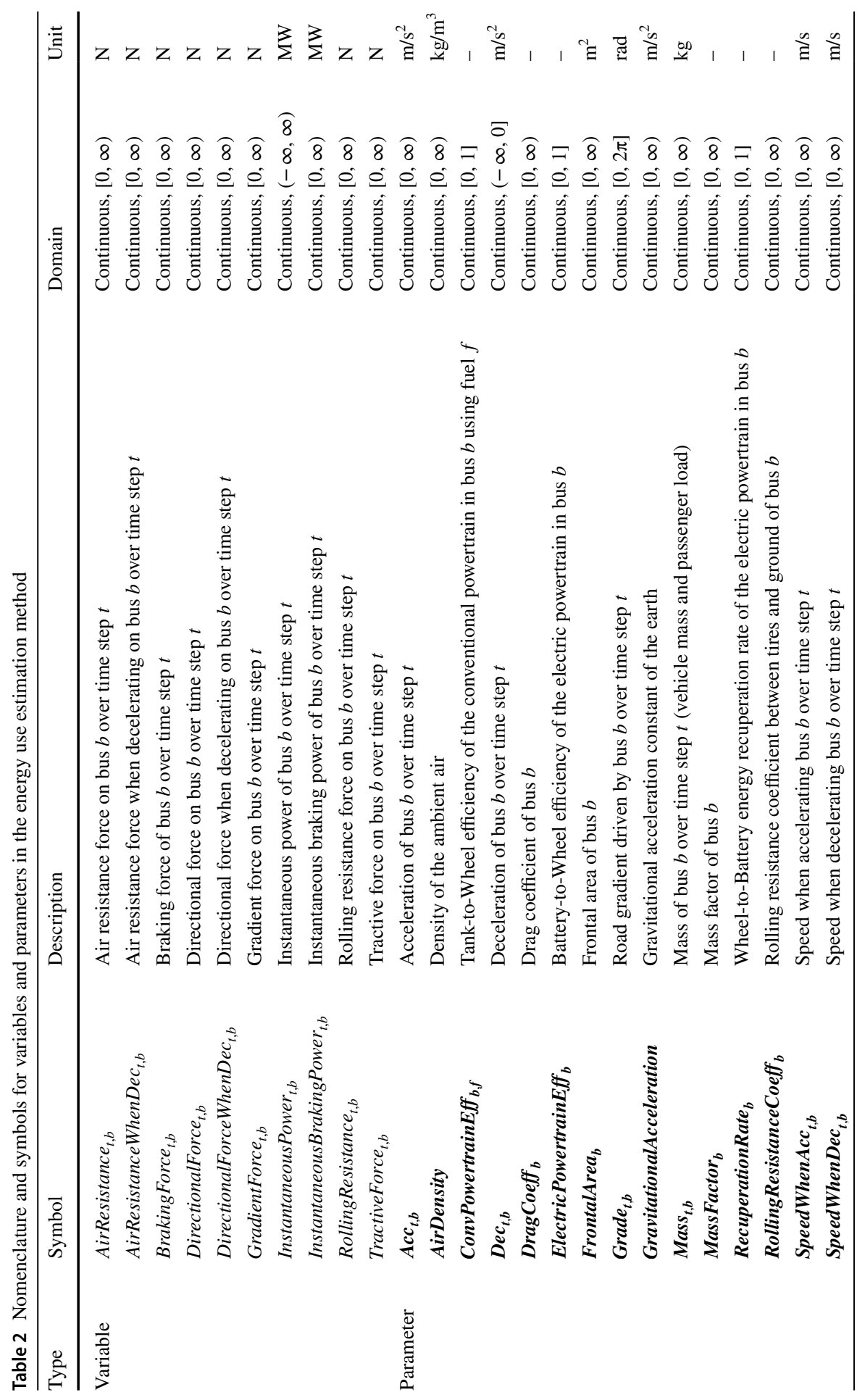


the engine load in a vehicle given by the tractive force and speed of the vehicle (26). The tractive force is the sum of the air resistance force (27), gradient force (28), rolling resistance force (29) and directional force (30). Similarly, the energy recovery rate from a regenerative braking system is estimated (31), but with the difference that the recuperation rate was considered including the forces occurring during deceleration (31)-(35). The recuperation rate is the conversion factor stating how much of the braking energy is converted into electrical energy and stored in the battery instead of being lost in form of heat during braking.

Note: the equations for exElectricityUseRate ${ }_{t, b}$ (23), exElectricityRecoveryRate ${ }_{t, b}$ (24) and exFuelUseRate t,b,f $_{\text {(31) include a division by Distance }}$, to obtain the unit mega-joule per kilometre $(\mathrm{MJ} / \mathrm{km})$ for the optimisation model above. Since exElectricityUseRate $_{t, b}$, exElectricityRecoveryRate ${ }_{t, b}$ and exFuelUseRate ${ }_{t, b, f}$ are calculated here, they are variables in this energy use estimation method, i.e. written in bold italics and non-bold italics compared to the real-time optimisation model formulation. The values of these variables are then the input data of the parameters exElectricityUseRate $_{t, b}$, exElectricityRecoveryRate ${ }_{t, b}$ and exFuelUseRate $_{t, b, f}$ in the optimisation model.

$$
\begin{aligned}
\text { exElectricityUseRate }_{t, b}= & \text { InstantaneousPower }_{t, b} \\
& \times \text { Duration }_{t} / \text { ElectricPowertrainEff }_{\boldsymbol{b}} / \text { Distance }_{t, \boldsymbol{b}} \\
\text { exFuelUseRate }_{t, b}= & \text { InstantaneousPower }_{t, b} \\
\times & \text { Duration }_{t} / \text { ConvPowertrainEff }_{\boldsymbol{b}, \boldsymbol{f}} / \text { Distance }_{t, \boldsymbol{b}} \\
\text { InstantaneousPower }_{t, b}=\text { TractiveForce }_{t, b} \times \text { SpeedWhenAcc }_{t, b} / 10^{6} & \\
\text { TractiveForce }_{t, b}= & \text { AirResistance }_{t, b}+\text { GradientForce }_{t, b} \\
& + \text { RollingResistance }_{t, b}+\text { DirectionalForce }_{t, b}
\end{aligned}
$$

AirResistance $_{t, b}=0.5 \times$ AirDensity DragCoeff $_{b} \times$ FrontalArea $_{b} \times$ SpeedWhenAcc $_{t, b}^{2}$

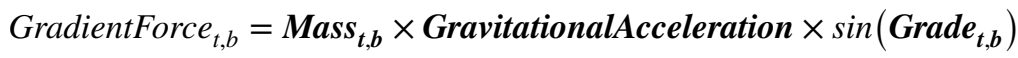

RollingResistance $_{t, b}=$ Mass $_{t, b} \times$ GravitationalAcceleration $\times \cos \left(\right.$ Grade $\left._{t, b}\right) \times$ RollingResistanceCoeff $_{b}$

$$
\text { DirectionalForce }_{t, b}=\text { Mass }_{t, b} \times A c c_{t, b} \times\left(1+\text { MassFactor }_{b}\right)
$$

$$
\text { exElectricityRecoveryRate }_{t, b}=\text { BrakingRequest }_{t, b} \times \text { Duration }_{t}
$$

$$
\times \text { RecuperationRate }_{b} / \text { Distance }_{t, b}
$$




$$
\begin{aligned}
& \text { InstantaneousBrakingPower }_{t, b}=\text { BrakingForce }_{t, b} \\
& \times \text { SpeedWhenDec }_{t, b} / 10^{6} \\
& \text { BrakingForce }_{t, b}=\text { AirResistanceWhenDec }_{t, b}+\text { GradientForce }_{t, b} \\
& + \text { RollingResistance }_{t, b}+\text { DirectionalForceWhenDec }_{t, b}
\end{aligned}
$$

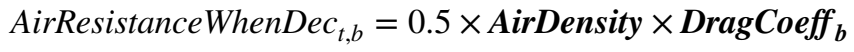

$$
\begin{aligned}
& \times \text { FrontalArea }_{b} \times \text { SpeedWhenDec }{ }_{t, b}^{2} \\
& \text { DirectionalForceWhenDec }_{t, b}=\text { Mass }_{\boldsymbol{t}, \boldsymbol{b}} \times \operatorname{Dec}_{t, b} \times\left(1+\text { MassFactor }_{\boldsymbol{b}}\right)
\end{aligned}
$$

\subsection{Code implementation}

The code implementation was done using the programming language Python 3.6.4 (Python Software Foundation 2018) and the Python library PuLP 1.6.8. (Mitchell et al. 2011) for the optimisation model. The PuLP default solver, called CBC (COIN-OR Branch-and-Cut MIP) solver (CBC 2019), was used to find optimal solutions. This solver was developed in the scope of the COIN-OR project (COIN-OR project 2018). In addition, other common Python libraries were used, such as Pandas 0.22.0 (McKinney 2010) and NumPy 1.14.0 (van der Walt et al. 2011). The simulation of one operation day was finished when all discrete time intervals between start time and end time of the simulation had been optimised and simulated. An operation day started at 4:30:00 a.m. and ended at 11:59:59 p.m. The duration of one discrete time interval was set to $180 \mathrm{~s}$ that was divided into time steps of $10 \mathrm{~s}$. The duration of $180 \mathrm{~s}$ was selected based on some tests that showed that longer time intervals resulted in significantly longer solving times for the optimisation model. More information for the preparation of the bus operation data is provided in the supplementary material.

\section{Case study: the C40-city Curitiba in Brazil}

The city of Curitiba in Southern Brazil is used as a case study for demonstration purposes of the real-time optimisation approach and for the comparison of the bus deployment scenarios and five management strategies concerning the charging schedule and/or all-electric operation. The city committed to introduce low-emission buses in the scope of a C40 network initiative (C40 2015) and, for example, one plug-in hybrid-electric bus as well as one battery-electric bus were tested during the time period 2015-2017 (URBS 2015; Volvo Bus Corporation 2016a). The electrification progress in Curitiba's bus transport system follows a pattern representative for many other cities. In those, small-scale tests of the 
aforementioned types of buses have been conducted; see, e.g., cities mentioned in ZeEUS Project (2016). In addition, Curitiba possesses a large amount of open data that was used to test the real-time optimisation model (UFPR 2017).

In fact, Curitiba has been famous for its development and implementation of the BRT concept since the 1970s. The BRT concept has been adopted in several cities since then. Curitiba's BRT system consists of seven BRT routes and two express BRT routes (i.e. fewer bus stations per distance) on which a few articulated buses (chassis length: $18 \mathrm{~m}$ ) and predominately bi-articulated buses (chassis length: $28 \mathrm{~m}$ ) are operated (Fig. 2a). Curitiba's BRT system has two types of bus stations, namely tube stations and terminal stations. A tube station is a glass tubeshaped regular bus station, whereas a terminal station is a large transfer hub that connects BRT routes with each other as well as to many regular bus routes in the city's bus transport system.

\subsection{System boundary}

No charging stations are currently implemented in Curitiba, and therefore, theoretical locations had to be considered as input data for the parameters in the optimisation model. Here, a previously presented approach of a local scientific study by Sebastiani et al. (2016) was taken up again, who placed charging stations at terminal stations. At least three reasons make terminal stations an interesting starting point for the placement of charging stations: (1) the spatial area of a terminal station is quite large, which gives flexibility for finding suitable locations; (2) most of the terminal stations are at the beginning/end of bus routes, where buses usually have longer dwell times, which consequently allow longer charge times; and (3) many routes and buses share the same terminal stations and, therefore, a high utilisation rate for charging stations can be presumably achieved.

Since the simulation of the whole BRT system would have required computer hardware with a higher performance than an ordinary laptop as used in this study or would have resulted in much longer computational times, a small sub-system within Curitiba's BRT system was chosen for demonstration. Furthermore, the objective is to discover insights from a tractable case, which can be lost by scaling the analysis.

Two criteria were used to identify a suitable sub-system: (1) a terminal station should be shared by at least three BRT routes; and (2) the necessity for the real-time optimisation model to make a decision when more than one bus needs to be charged at the same time should amount to at least $70 \%$ of the operation time. The percentage of $70 \%$ was chosen to use an example case, in which the formulated problem is distinctly existing. A data analysis was performed to evaluate both criteria for the bus operation dataset from the 31 October 2017. Table 3 shows the determination of the system boundary. The first criterion was fulfilled by six terminal stations. Out of these six terminal stations, only the terminal station Capão Raso fulfilled the second criterion. Based on this ad-hoc analysis, the system boundary comprises the terminal station Capão Raso with one charging station and the four BRT routes $(203,502$, 602, 603) that approach this terminal (Fig. 2b). 


\subsection{Scenarios, management strategies and input data}

The city of Curitiba started an open data online platform in 2017, from which all data of the real-world bus operations and locations of bus stations were retrieved (UFPR 2017). Two weeks of operations were simulated for the period 8-21 January 2018. The bus operation data from the currently operated conventional buses was used as input data in the optimisation model, because neither hybrid-electric nor plug-in hybrid-electric buses have been operated in Curitiba's BRT system. Biarticulated buses were considered in the simulations, since this type of bus is predominantly operated in Curitiba's BRT system.

Three bus deployment scenarios were simulated: (1) the business-as-usual (BAU) scenario that represents the current situation in which conventional bi-articulated buses are used. This type of bus uses diesel as a fuel in a conventional powertrain, which does not have any electric motor for propulsion and thus, all-electric drive is impossible; (2) a hybrid-electric (HYB) scenario that represents the hypothetical situation in which hybrid-electric bi-articulated buses are used. This type of bus has got a small battery and a regenerative braking system for electricity recovery, but neither uses opportunity charging nor overnight charging. Thus, hybrid-electric buses only use regenerative braking to convert braking energy into electricity that is then used for all-electric drive. Consequently, this amount of electricity is internally generated in the powertrain. Otherwise, the main source of energy is diesel that is used in an internal combustion engine; (3) a plug-in hybrid-electric (PLUG) scenario that represents the hypothetical situation in which plug-in hybrid-electric bi-articulated buses are used. This type of bus has got a larger battery, a regenerative braking system for electricity recovery, and can use both opportunity charging as well as overnight charging at the bus depot. Moreover, the five management strategies were tested in the case of the PLUG scenario. An overview of all scenarios and management strategies is given in Table 4. A summary of the input data for the three scenarios is provided in Table 5.

\subsection{Validation of the energy use estimation method}

For the validation of the energy use estimation method for its application to simulate bi-articulated buses in the case of Curitiba using the input data from Table 5, the same BRT routes and bus operation data were used as in the scenarios later, i.e. BRT routes 203, 502, 602 and 603, and the bus operation data for the period 8-21 January 2018. The descriptive statistics of the validation test are provided in Table 1.

Firstly, the energy use estimation method was validated for the case that conventional powertrains are used in the bi-articulated buses. The bus fleet, operated on BRT routes 203, 502, 602 and 603, had an average energy use of (38.07 \pm 3.11$) \mathrm{MJ} /$ $\mathrm{km}$. Furthermore, the energy use rate differs considerably between the BRT routes with mean values ranging from $33.62 \mathrm{MJ} / \mathrm{km}$ to $40.59 \mathrm{MJ} / \mathrm{km}$. The estimations and variations are in line with findings in the study by Dreier et al. (2018), who used technical in-depth simulations and estimated a mean energy use rate of $29.92 \mathrm{MJ} / \mathrm{km}$ for conventional bi-articulated buses with a value range of (18.55-40.50) MJ/km. 

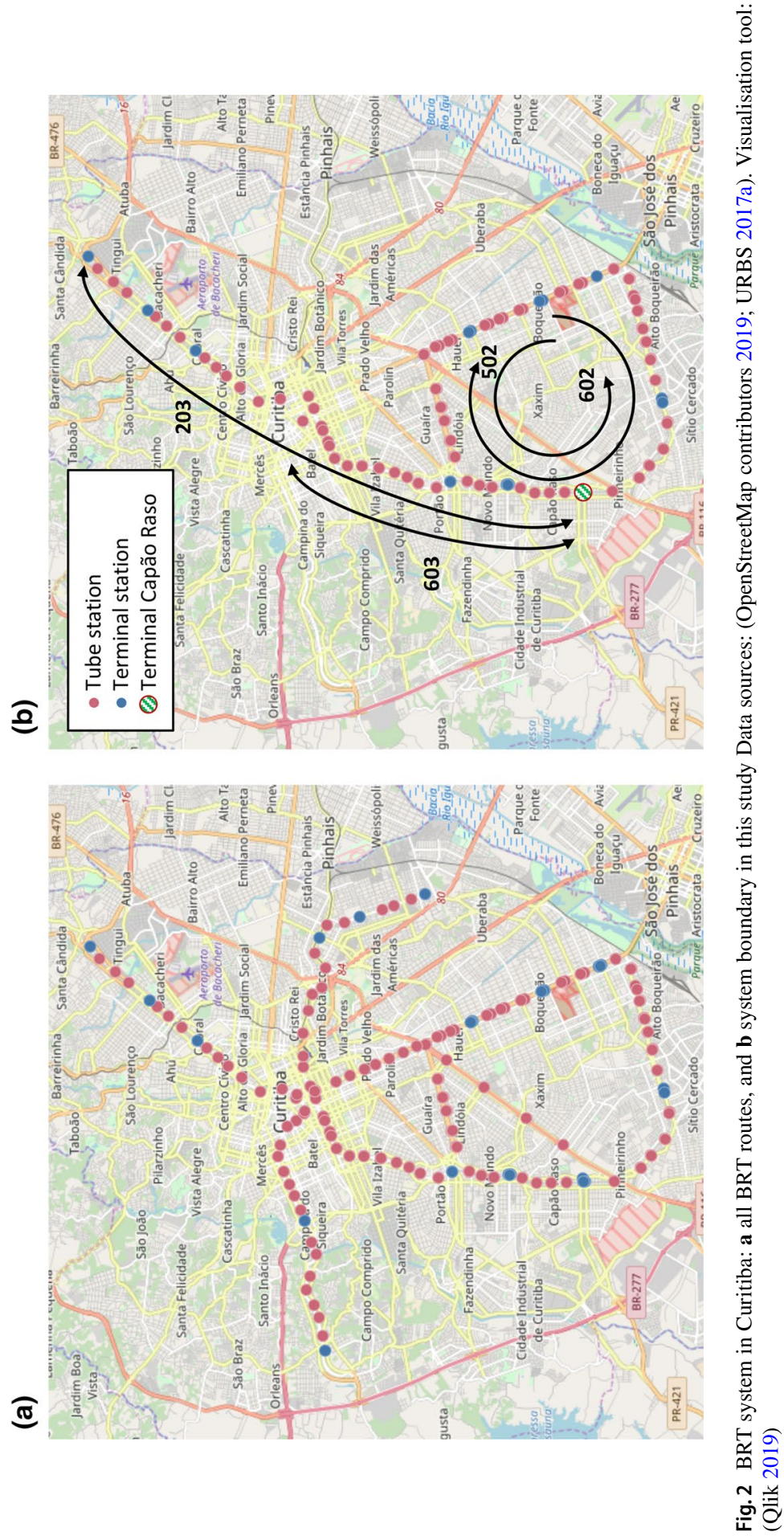


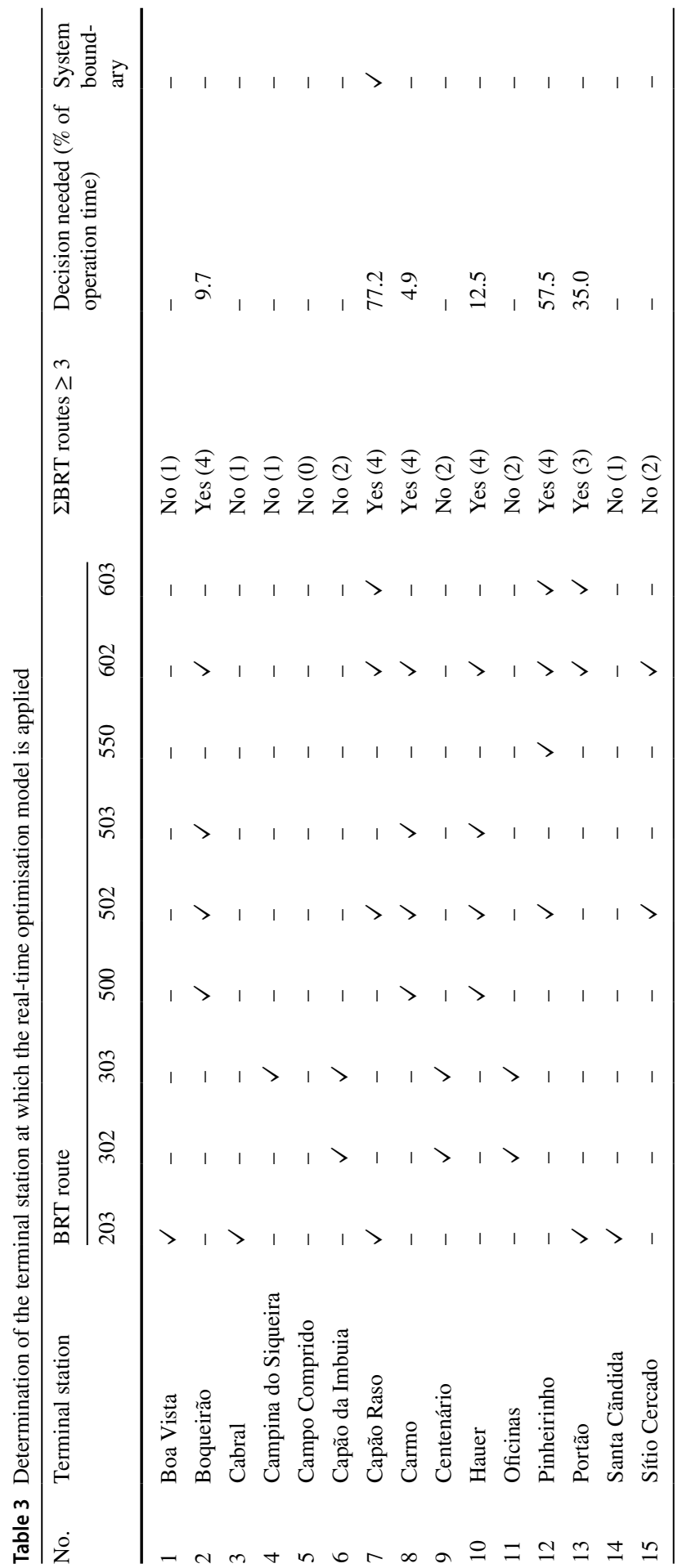


Another source for comparison is the BRT Data online platform (Global BRT Data 2015 ), that states a mean value of $32.51 \mathrm{MJ} / \mathrm{km}$ for conventional bi-articulated buses in Curitiba's BRT system. The value of $32.51 \mathrm{MJ} / \mathrm{km}$ was calculated from the stated fuel economy of $1.12 \mathrm{~L} / \mathrm{km}$ in Global BRT Data (2015) considering the locally used fuel biodiesel blend B7 in Curitiba in 2015. Fuel properties data was retrieved from Canakci and van Gerpen (2003) for petroleum diesel (LHV: $42.640 \mathrm{MJ} / \mathrm{kg}$; density: $0.854 \mathrm{~kg} / \mathrm{L}$ ) and biodiesel 100\% (B100) (LHV: $37.388 \mathrm{MJ} / \mathrm{kg}$; density: $0.881 \mathrm{~kg} / \mathrm{L}$ ). With this information, the fuel properties of biodiesel blend B7 (LHV: $42.272 \mathrm{MJ} /$ $\mathrm{kg}$; density: $0.856 \mathrm{~kg} / \mathrm{L}$ ) were calculated based on the volumetric share of $93 \%$ petroleum diesel and 7\% B100.

Secondly, the energy use estimation method was validated for the case that electric powertrains are used in the bi-articulated buses. To the best of our knowledge, electric bi-articulated buses have not been operated in any BRT system on the world at the time of this study, but those are currently under development; see, e.g., Busworld (2018). Meanwhile, electric two-axle buses have been tested and used to a relatively large extent in cities. In the case of Curitiba, one electric two-axle bus was tested by the local public transport and urban development company in Curitiba URBS - Urbanization of Curitiba S/A (URBS 2017a). They found an electricity use rate of $4.68 \mathrm{MJ} / \mathrm{km}$, or electricity economy of $0.77 \mathrm{~km} / \mathrm{kWh}$ as originally stated in URBS (2015). This type of bus has a permitted gross vehicle weight (GVW) of 19 tonnes (BYD 2019), and thus, a mass-specific electricity use rate of $0.25 \mathrm{MJ} / \mathrm{km}$ per tonne of GVW. Comparing this value to our estimations of $(13.22 \pm 1.08) \mathrm{MJ} /$ $\mathrm{km}$, or respectively, $(0.29 \pm 0.02) \mathrm{MJ} / \mathrm{km}$ per tonne of GVW [GVW of a bi-articulated bus: 45.3 tonnes (Volvo Bus Corporation 2018b)], indicates a relatively close mass-specific estimation capability when relating to the GVW and assuming similar ratios between GVW and passenger load of the applied energy use method for an electric powertrain in a bi-articulated bus in this study. The observed small deviation could be potentially caused by different driving cycles and/or different overall energy efficiencies in the electric powertrains. Nevertheless, this simple method approximates the findings from the real-world physical tests acceptably close.

Thirdly, the energy use estimation method was validated for the case that plug-in hybrid-electric powertrains are used in the bi-articulated buses. The operation is distinguished between charge-depleting (CD) mode and charge-sustaining (CS) mode. $\mathrm{CD}$-mode is the operation mode in which all-electric drive is used until the battery is depleted to the lower bound of the SOC $\left(\boldsymbol{S O C l o w}_{\boldsymbol{b}}\right)$. The CD-mode ends then, and the CS-mode starts in which all-electric drive is used if SOC is larger than SOClow $\boldsymbol{b}_{\boldsymbol{b}}$, otherwise the international combustion engine is used. The CS-mode is the functional principle of hybrid-electric buses. Here, the battery in a bus is only charged with electricity recovered from the regenerative braking system. This increases the SOC again until it is higher or equal to $\boldsymbol{S O C l o w}_{\boldsymbol{b}}$, so that the electric motor can be used. As previously shown, the energy use method estimates representative numeric values for both fuel use in the case of a conventional powertrain and electricity use in the case of an electric powertrain. Therefore, the validation of plug-in hybridelectric buses requires testing of the functioning of the CD-mode and CS-mode, i.e. interplay of conventional and electric powertrain characteristics. Thus, the trend of the SOC in the battery over the driven distance is important, since it shows how 


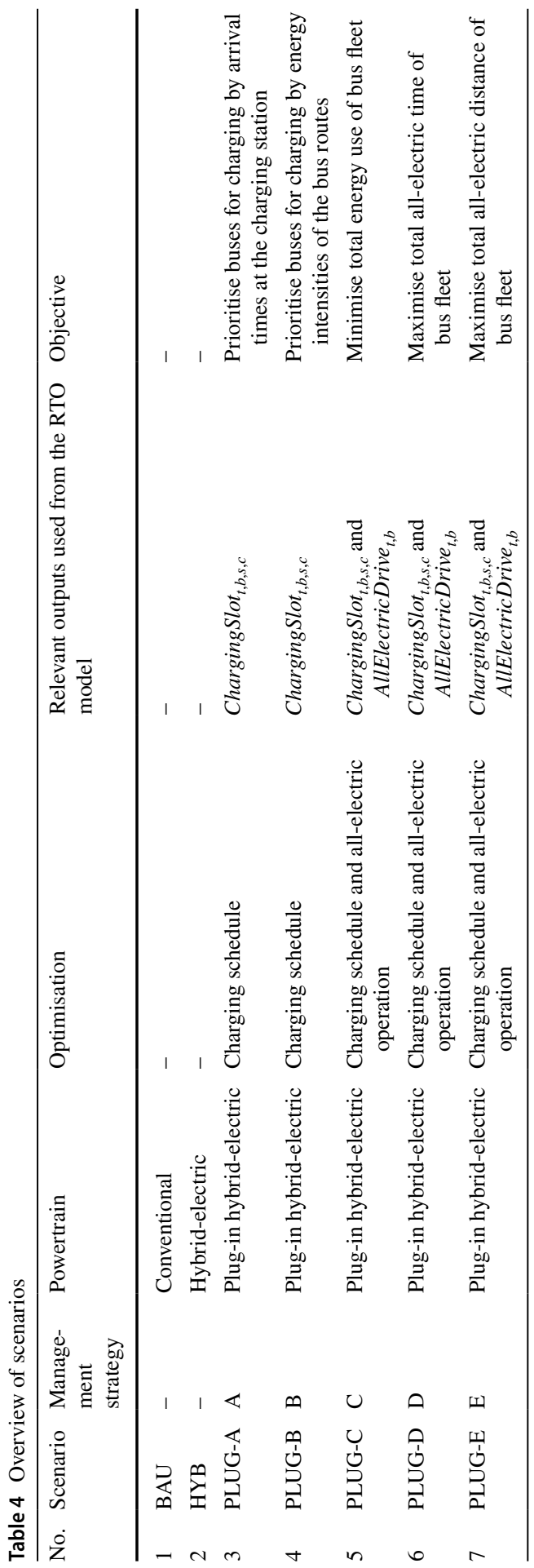


Table 5 Technical input data of the buses and environment conditions for the application of the real-time optimisation model in the case of Curitiba

\begin{tabular}{|c|c|c|c|c|c|}
\hline \multirow[t]{2}{*}{ Simulation } & \multicolumn{3}{|l|}{ Scenarios } & \multirow[t]{3}{*}{ Unit } & \multirow[t]{3}{*}{ Source } \\
\hline & BAU & HYB & $\begin{array}{l}\text { PLUG } \\
(\mathrm{A} / \mathrm{B} / \mathrm{C} / \mathrm{D} / \mathrm{E})\end{array}$ & & \\
\hline Bus powertrain & Conventional & Hybrid-electric & $\begin{array}{l}\text { Plug-in } \\
\text { hybrid-electric }\end{array}$ & & \\
\hline Bus chassis & $\mathrm{Bi}$-articulated & $\mathrm{Bi}$-articulated & Bi-articulated & & \\
\hline SOCinit $_{b}$ & - & 55 & 85 & $\%$ & Assumption ${ }^{\mathrm{a}, \mathrm{g}}$ \\
\hline SOClow $_{b}$ & - & 20 & 20 & $\%$ & Assumption ${ }^{\mathrm{b}, \mathrm{g}}$ \\
\hline SOChigh $_{b}$ & - & 90 & 90 & $\%$ & Assumption ${ }^{\mathrm{b}, \mathrm{g}}$ \\
\hline Capacity $_{b}$ & - & $3.75 \times 3.6$ & $45.3 \times 3.6$ & MJ & Calculation $^{\mathrm{c}, \mathrm{d}}$ \\
\hline ChargingPower $_{c, s}$ & - & - & 0.450 & MW & (Siemens 2018) \\
\hline ElectricPowertrainEff $_{b}$ & - & 72 & 72 & $\%$ & Calculation $^{\mathrm{e}, \mathrm{g}}$ \\
\hline ConvPowertrainEff ${ }_{b, f}$ & 25 & 25 & 25 & $\%$ & $\begin{array}{l}\text { (Nylund et al. } \\
\text { 2007) }\end{array}$ \\
\hline RecuperationRate $_{b}$ & - & 21 & 21 & $\%$ & $\begin{array}{l}\text { (Perrotta et al. } \\
2012)^{\mathrm{g}}\end{array}$ \\
\hline AirDensity & 1.225 & 1.225 & 1.225 & $\mathrm{~kg} / \mathrm{m}^{3}$ & (ISO 1975) \\
\hline GravitationalAcceleration & 9.80655 & 9.80655 & 9.80655 & $\mathrm{~m} / \mathrm{s}^{2}$ & (ISO 1975) \\
\hline RollingResistanceCoeff $_{b}$ & 0.01 & 0.01 & 0.01 & - & (Gillespie 1992) \\
\hline MassFactor $_{b}$ & 0.1 & 0.1 & 0.1 & - & (Yu et al. 2016b) \\
\hline DragCoeff $_{b}$ & 0.70 & 0.70 & 0.70 & - & (Dreier 2015) \\
\hline FrontalArea $_{b}$ & 8.22 & 8.22 & 8.22 & $\mathrm{~m}^{2}$ & $\begin{array}{l}\text { (Dreier et al. } \\
\text { 2018) }\end{array}$ \\
\hline $\operatorname{Mass}_{t, b}$ & 41783 & 41783 & 41783 & $\mathrm{~kg}$ & Calculation $^{\mathrm{f}}$ \\
\hline
\end{tabular}

${ }^{\mathrm{a}} \mathrm{HYB}$ scenario: initial SOC at operation start was assumed to be in the middle of $\mathrm{SOC}_{\mathrm{low}}$ and $\mathrm{SOC}_{\mathrm{high}}$, since the SOC level varies between these boundaries depending on electricity use and recovery. PLUG scenario: Initial SOC at operation start was assumed to be at $85 \%$, because buses are usually charged with slow charging at the bus depot overnight. The reason that $\mathrm{SOC}_{\text {init }}$ is $5 \%$-points below $\mathrm{SOC}_{\mathrm{high}}$ is that constraint (16) will not be violated in the simulations at the beginning

${ }^{\mathrm{b}}$ Usable capacity of a battery, i.e. capacity between $\mathrm{SOC}_{\mathrm{low}}$ and $\mathrm{SOC}_{\mathrm{high}}$, in a bus is usually between $50-70 \%$ instead of $100 \%$ of the nominal capacity. This prevents aging and thus, increases the lifetime (Hõimoja et al. 2012; Rosenkranz 2003; Wikner and Thiringer 2018). In this study, the usable capacity is set at $70 \%$ of the nominal capacity

${ }^{\mathrm{c}}$ Nominal capacity for a hybrid-electric bi-articulated bus was assumed to be of $3.75 \mathrm{kWh}$ using linear interpolation with a ratio of $0.0828 \mathrm{kWh}$ per tonne of the permitted gross vehicle weight (GVW) based on the relation between the nominal capacity of $2.4 \mathrm{kWh}$ for a hybrid-electric articulated bus having a GVW of 29 tonnes (Volvo Bus Corporation 2018a). GVW of a bi-articulated bus: 45.3 tonnes (Volvo Bus Corporation 2018b). The factor 3.6 is the unit conversion factor from $\mathrm{kWh}$ to $\mathrm{MJ}$

${ }^{\mathrm{d}}$ Nominal capacity for a plug-in hybrid-electric bi-articulated bus was assumed to be of $45.3 \mathrm{kWh}$ using linear interpolation with a ratio of $1 \mathrm{kWh}$ per tonne of GVW based on the ratio between the nominal capacity of $19 \mathrm{kWh}$ for a plug-in hybrid-electric two-axle bus and its GVW of 19 tonnes (Volvo Bus Corporation 2016b). GVW of a bi-articulated bus: 45.3 tonnes (Volvo Bus Corporation 2018b). The factor 3.6 is the unit conversion factor from $\mathrm{kWh}$ to $\mathrm{MJ}$

${ }^{\mathrm{e}}$ The Tank-to-Wheel (TTW) energy efficiency of an electric powertrain was calculated with the product of the efficiencies of the powertrain components: electric motor efficiency: 90\% (Jurca et al. 2015); battery discharge efficiency: 94.5\% (Du et al. 2017); battery traction motor efficiency: $88.9 \%$ (Du et al. 2017); and transmission efficiency: $95.5 \%$ (Du et al. 2017) 
Table 5 (continued)

${ }^{\mathrm{f}}$ The mass of a bus was calculated by using the GVW minus the product of passenger carrying capacity (PCC) times weight of one passenger times occupancy rate. GVW of a plug-in hybrid-electric two-axle bus: 19 tonnes (Volvo Bus Corporation 2016b); GVW of a conventional bi-articulated bus: 45.3 tonnes (Volvo Bus Corporation 2018b); PCC of a plug-in hybrid-electric two-axle bus: 105 (Volvo Bus Corporation 2016b); PCC of a conventional bi-articulated bus: 250 passenger (URBS 2017a); weight of one passenger: $67 \mathrm{~kg}$, same assumption as used by Dreier et al. (2018); occupancy rate: 50\% (Dreier et al. 2018)

${ }^{\mathrm{g}}$ Values stated in percent (\%) must be written as decimals to be valid as input data in the optimisation model

electricity use in the electric motor, electricity recovery with regenerative braking, and the functioning of the hybrid control strategies work depending on the SOC. For this test, the simulated SOC trends of eight randomly chosen plug-in hybrid-electric bi-articulated buses, i.e. two buses simulated for each BRT route in this study, for the operation using data from the 8 January 2018 are plotted in Fig. 3. As shown, the SOC levels for all buses start at the initial SOC of $85 \%$ and follow decreasing trends with some upwards fluctuations due to regenerative braking until $\boldsymbol{S O C l o w}_{\boldsymbol{b}}$ is surpassed. As expected, the CD-mode stops, and then the CS-mode is used. From this point, the SOC fluctuates around SOClow $\boldsymbol{S}_{\boldsymbol{b}}$ due to the alternation between regenerative braking and all-electric drive; see, e.g., 'Bus_1_203'.

The plug-in hybrid-electric bi-articulated buses in this study were dimensioned based on an interpolation from a plug-in hybrid-electric two-axle bus considering the ratio of nominal capacity of the battery and its GVW, see the footnotes of Table 5. The bus manufacturer of the latter states that the CD-mode operation should last for $7 \mathrm{~km}$ (Volvo Bus Corporation 2016b). Figure 3 shows that SOC levels in the battery of most tested buses almost reach the $\boldsymbol{S O C l o w}_{\boldsymbol{b}}$ after around $7 \mathrm{~km}$ of CD-mode. One exception can be observed in the case of the bus 'Bus_1_502' that has still a much higher SOC after $7 \mathrm{~km}$ of driving. Considering that BRT route 502 has the lowest energy use values as shown in Table 6, this particular bus probably operated within a smooth traffic flow and hence, higher energy-efficient driving was possible. An indication for this is shown by the relatively constant sections of the SOC over distance. Moreover, bus 'Bus_1_602' is charged to $\mathrm{SOC}_{\text {high }}(90 \%)$ after approximately $2 \mathrm{~km}$ of driving, which also shows that opportunity charging works as expected in the simulations.

Overall, the behaviour of both CD-mode and CS-mode functions as expected for the buses, and also shows that the operation within the bus fleet can differ. The latter is, in turn, one of the interesting aspects to be considered for the real-time optimisation approach. Lastly, since the CS-mode works as expected for the plug-in hybridelectric bi-articulated, the estimations from simulating hybrid-electric bi-articulated buses can be considered as validated, too.

\subsection{Statistical analysis of the BRT routes}

After the validation of the energy use estimation method, another statistical test was performed to test whether the four considered BRT routes differ statistically 
significantly in their energy use rate or not. This is an important aspect, since the real-time optimisation model aims to maximise benefits from the electrification of the bus transport system by considering route-specific and time-specific driving cycles of the buses. Furthermore, the PLUG scenario managed by strategy B will make decisions based on the findings from this statistical analysis. Therefore, statistical significance had to be evaluated before strategy B could be used in the optimisation model.

For the evaluation, descriptive statistics, a one-way between-groups ANOVA (Analysis of Variance), and post hoc tests were conducted to determine whether the means of the energy use rates of buses operated on the four BRT routes for each day differ statistically in a significant way or not. The buses were divided into four groups according to the BRT route numbers 203, 502, 602 and 603. The findings from the statistical tests are exemparily presented in the following for the dataset from the 9 January 2018. The complete results for all dates containing descriptive statistics, ANOVA and post hoc tests are provided in the supplementary material. The calculations were done using the software Past 3.x, version 3.18 (Hammer et al. 2001).

The significance level $\alpha$ (alpha) was set at $\alpha=0.05$. Levene's test of homogeneity of variances for means gave a significance value of $p=0.698$, i.e. $p>0.05$ indicates no violations of the assumption of homogeneity of variance. Hence, further tests with the underlying assumption of a normal distribution could be conducted. The four BRT routes are statistically significantly different at the $\mathrm{p}<0.05$ level in the energy use rate of the buses: $\mathrm{F}$ (degrees of freedom between groups: 3; degrees of freedom within groups: 99$)=262.8, \mathrm{p}<0.05$. Although statistical significance was reached, the actual mean values of energy use rates between BRT routes can be grouped into two groups: a group containing more energy-intensive BRT routes $203($ mean $=40.36 \mathrm{MJ} / \mathrm{km} ; \mathrm{SD}=0.91 \mathrm{MJ} / \mathrm{km})$ and $603($ mean $=38.57 \mathrm{MJ} / \mathrm{km}$; S.D. $=1.17 \mathrm{MJ} / \mathrm{km}$ ), and another group containing less and similar energyintensive BRT routes $502($ mean $=33.64 \mathrm{MJ} / \mathrm{km} ; \mathrm{SD}=1.24 \mathrm{MJ} / \mathrm{km})$ and 602 $($ mean $=33.75 \mathrm{MJ} / \mathrm{km} ; \mathrm{SD}=0.96 \mathrm{MJ} / \mathrm{km})$. The effect size was 0.8841 when calculating omega squared. Post-hoc comparisons were done with Tukey's HSD (Honestly Significant Difference) test and indicate that BRT routes 502/602 do not statistically significantly differ from each other, while the other two BRT routes 203 and

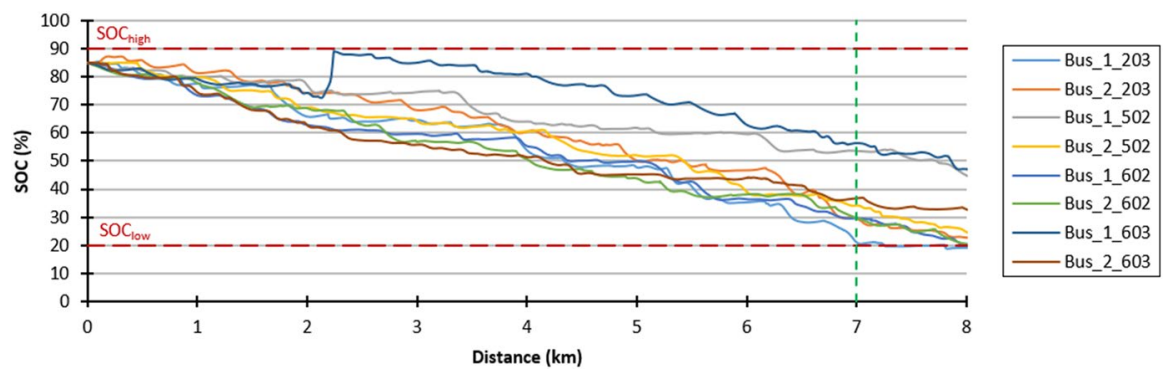

Fig. 3 State-of-charge (SOC) trends over distance for eight randomly chosen plug-in hybrid-electric biarticulated buses simulated on BRT routes 203, 502, 602 and 603 considering bus operation data from the 8 January 2018 


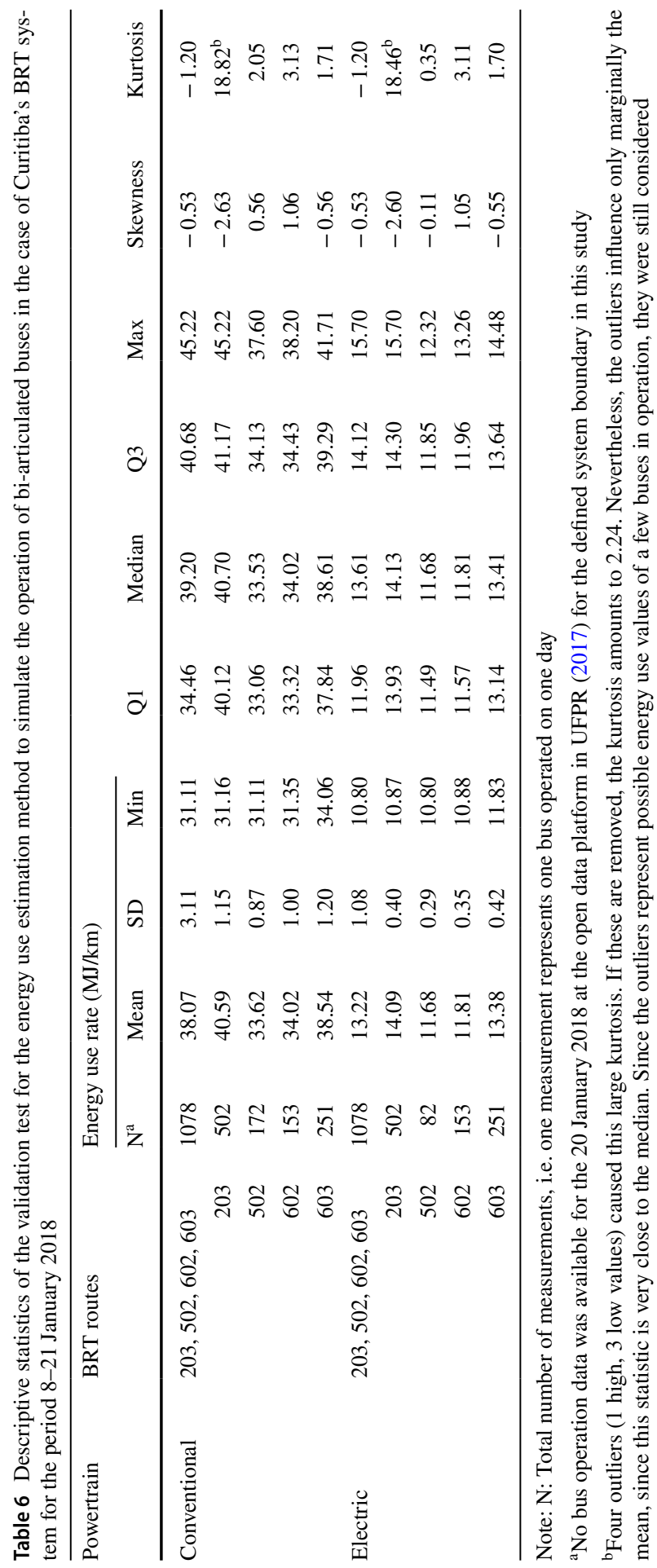


603 differ statistically significantly from each other as well as from BRT routes 502 and 602. It is not surprising that BRT routes 502 and 602 are quite similar, since they operate clockwise and counter-clockwise on the same track through the city and consequently, have similar traffic conditions. Hence, they could be actually considered as one BRT route, as bus routes are usually operated in two directions rather than only one direction.

As shown, the buses operated on 203, 502/602 and 603 BRT routes are statistically significantly different from each other concerning their means of the energy use rates. Therefore, the system boundary comprising these BRT routes and terminal station Capão Raso is also suitable for the optimisation model considering the results from the statistical analysis.

Regarding the implementation of strategy $\mathrm{B}$ in the optimisation model: BRT routes will be prioritised descending in the following order: 203, 603, 502/602. BRT routes 502 and 602 are not statistically significantly different from each other and therefore, both got the same numeric value for the parameter LevelOfImportance ${ }_{t, b, s}$ in the simulations.

\section{Results}

The operation of the bus fleet differs from the simulated days in terms of total operation distance and total operation time and so do the absolute numbers for the estimated total energy savings and total all-electric operation. In the following, the total energy use of the bus fleet (TEU) is related to the total distance driven by the bus fleet, i.e., the functional unit is in energy (mega-joule: MJ) per distance (kilometre: $\mathrm{km}$ ) abbreviated as $\mathrm{MJ} / \mathrm{km}$. The total energy savings (TES) are expressed in percent (\%), since the total energy use estimated in each scenario is compared to the total energy use estimated in the BAU scenario. All-electric operation is stated by the total all-electric distance of the bus fleet (TAED) related to the total operation distance as well as by the total all-electric time of the bus fleet (TAET) related to the total operation time. As both give ratios, they are presented in percent (\%) in the following. In addition to the scenarios, the mean value of all PLUG scenarios (i.e. PLUG-A, B, C, D, and E) is shown as PLUG without any suffix.

Brief overview of figures and tables: The mean values of total energy use and total energy savings are shown in Fig. 4, and the mean values of the share of total all-electric time (in \%) versus the share of total all-electric distance (in \%) are shown in Fig. 5. Descriptive statistics of the estimations are provided in Table 7 and with more details in the supplementary material.

\subsection{Energy savings}

As expected due to the higher overall energy efficiency of the electric powertrain compared to the conventional powertrain, the energy use decreases with increasing degree of electrification (HYB: $31.50 \mathrm{MJ} / \mathrm{km}, 17 \%$ TES; PLUG: $27.82 \mathrm{MJ} / \mathrm{km}, 27 \%$ TES) compared to the BAU scenario (38.09 MJ/km), see Fig. 4. The considerable 
energy savings were achieved due to three reasons: (1) all-electric drive could be used for propulsion using electricity obtained from the regenerative braking system. This technology achieved energy savings of $17 \%$ as shown in the HYB scenario. The same applies to the PLUG scenarios as those buses also used regenerative braking systems. Additionally, the PLUG scenario had two additional advances that allowed them to achieve additional 10\%-points of energy savings. (2) Buses employed larger batteries that could be recharged during operation using opportunity charging. Consequently, more all-electric drive was possible that resulted in additional 8\%-points of energy savings. Moreover, (3) batteries were charged with overnight charging to $\left(\right.$ SOCinit $\left._{b}\right)$. The all-electric drive operation using electricity from operation start at SOCinit $_{\boldsymbol{b}}$ until the end of the charge-depleting mode at $\boldsymbol{S O C l o w}_{\boldsymbol{b}}$ resulted in additional $2 \%$-points of energy savings. Summing up the percentage points gives total energy savings of $27 \%$ in the PLUG scenarios on average. All calculations are provided in the supplementary material.

The PLUG scenarios including the five management strategies achieved considerable total energy savings (27\%), but only differ marginally between each other. This indicates that the degree of electrification reduces more energy use than any operational optimisation of the charging schedule and/or all-electric operation. Some observations can be made between the strategies, though.

It is counter-intuitive that PLUG-A (TEU: $27.65 \mathrm{MJ} / \mathrm{km}$ ) and PLUG-B (TEU: 27.67 MJ/km) achieve lower levels of total energy use than PLUG-C (TEU: $27.88 \mathrm{MJ} / \mathrm{km}$ ). The latter optimises the charging schedule and all-electric operation with the objective to minimise total energy use. The reason for this unexpected underperformance lays probably in the nature of the greedy algorithm. While it finds local minima for each of the optimised discrete time intervals, it does not imply to reach also a global minimum considering the whole operation day. Thus, it determines the best solution for the present time interval without any consideration of the consequences in the future. Meanwhile, buses were presumably charged during one time interval that, however, did not lead to the maximum possible reduction of total energy use in the remaining subsequent time intervals. Although, this risk was given, strategy C still achieved a lower energy use than strategies D (TEU: $27.96 \mathrm{MJ} / \mathrm{km}$ ) and E (TEU: $27.95 \mathrm{MJ} / \mathrm{km}$ ). However, the effort to implement management strategy

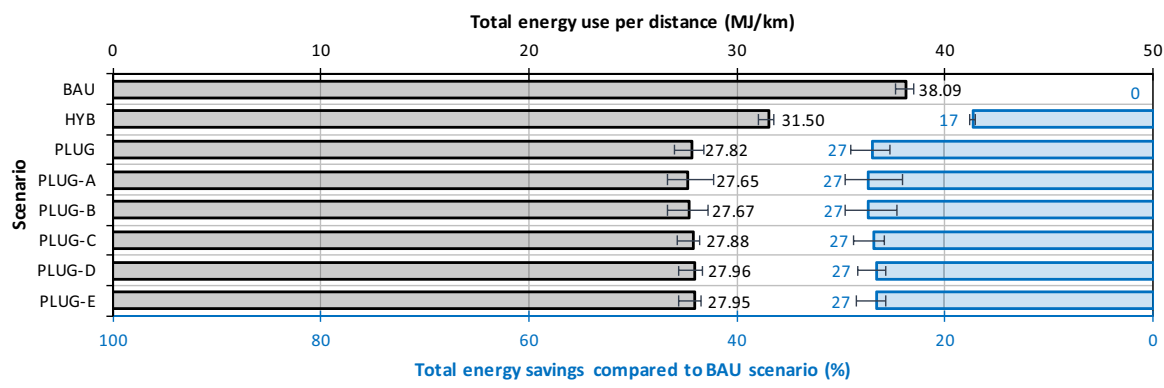

Fig. 4 Comparison of total energy use per distance of the bus fleet and total energy savings of the bus fleet in the respective scenario compared to the BAU scenario. Results are based on the mean values obtained from the simulations 


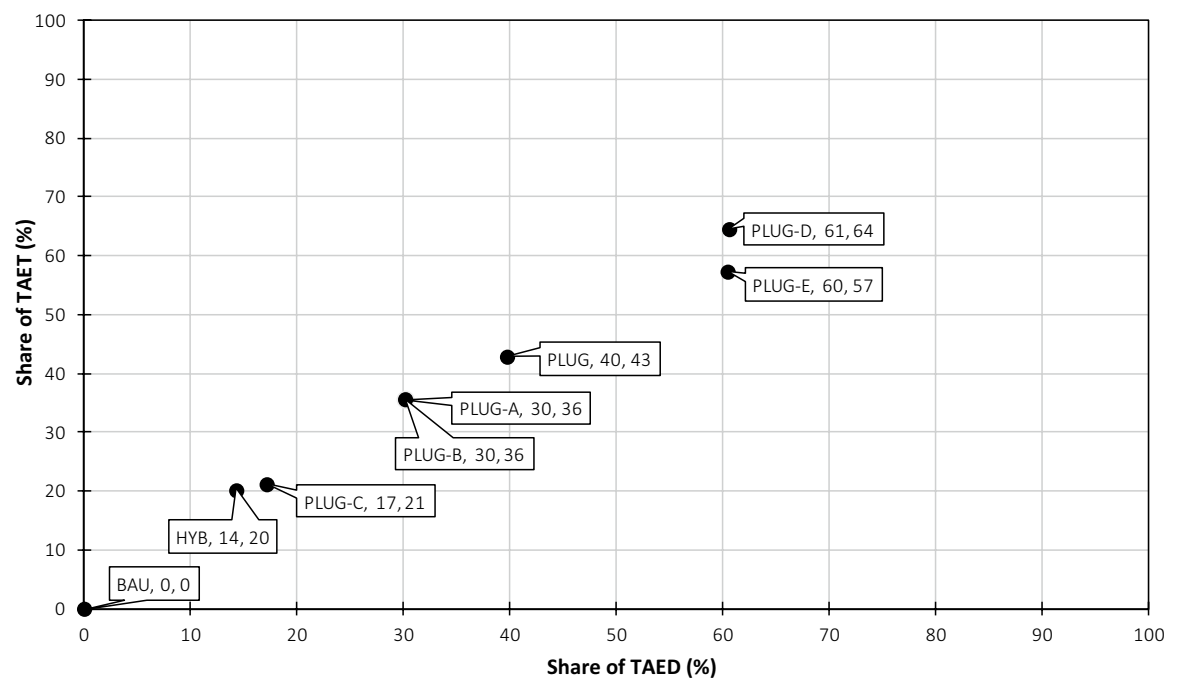

Fig. 5 Comparison of the total all-electric time of the bus fleet (TAET) and total all-electric distance of the bus fleet (TAED). Data labels are in the format of: [Scenario, share of TAED, share of TAET]. Results are based on the mean values obtained from the simulations

$\mathrm{C}$ and its low performance compared to strategies $\mathrm{A}$ and $\mathrm{B}$ led to the insights that strategies $\mathrm{A}$ and $\mathrm{B}$ are the preferred options to manage the charging schedule of the bus fleet concerning the objective of minimising total energy use. Besides, no significant difference was found for the estimations of total energy use and savings between the scenarios PLUG-A and PLUG-B. Consequently, management strategy A should be used instead of B considering the simplicity of its implementation.

It can be derived from the simulations for different degrees of electrification in the HYB and PLUG scenarios and the comparison of the five management strategies in the PLUG scenario compared to the BAU scenario, that a systematic change of the bus fleet by using plug-in hybrid-electric buses instead of conventional buses is much more effective than focusing on different management strategies for the charging schedule and/or all-electric operation concerning total energy savings. While this was found for total energy savings, the next section presents a significant difference for the all-electric operation that makes the consideration of management strategies relevant when aiming at optimising duration or distance of all-electric operation.

\subsection{All-electric operation}

As previously shown, the total energy savings are mainly influenced by the degree of electrification and not significantly further increased by any management strategy. However, this is not transferable to the share of all-electric operation. For example, Fig. 5 shows that the share of TAET is almost the same for HYB (20\%) and PLUG$\mathrm{C}(21 \%)$ as well as TAED is only 3\%-points lower for HYB (14\%) than for PLUG-C (17\%). In contrast, the other PLUG scenarios using strategies A, B, D or E achieved 


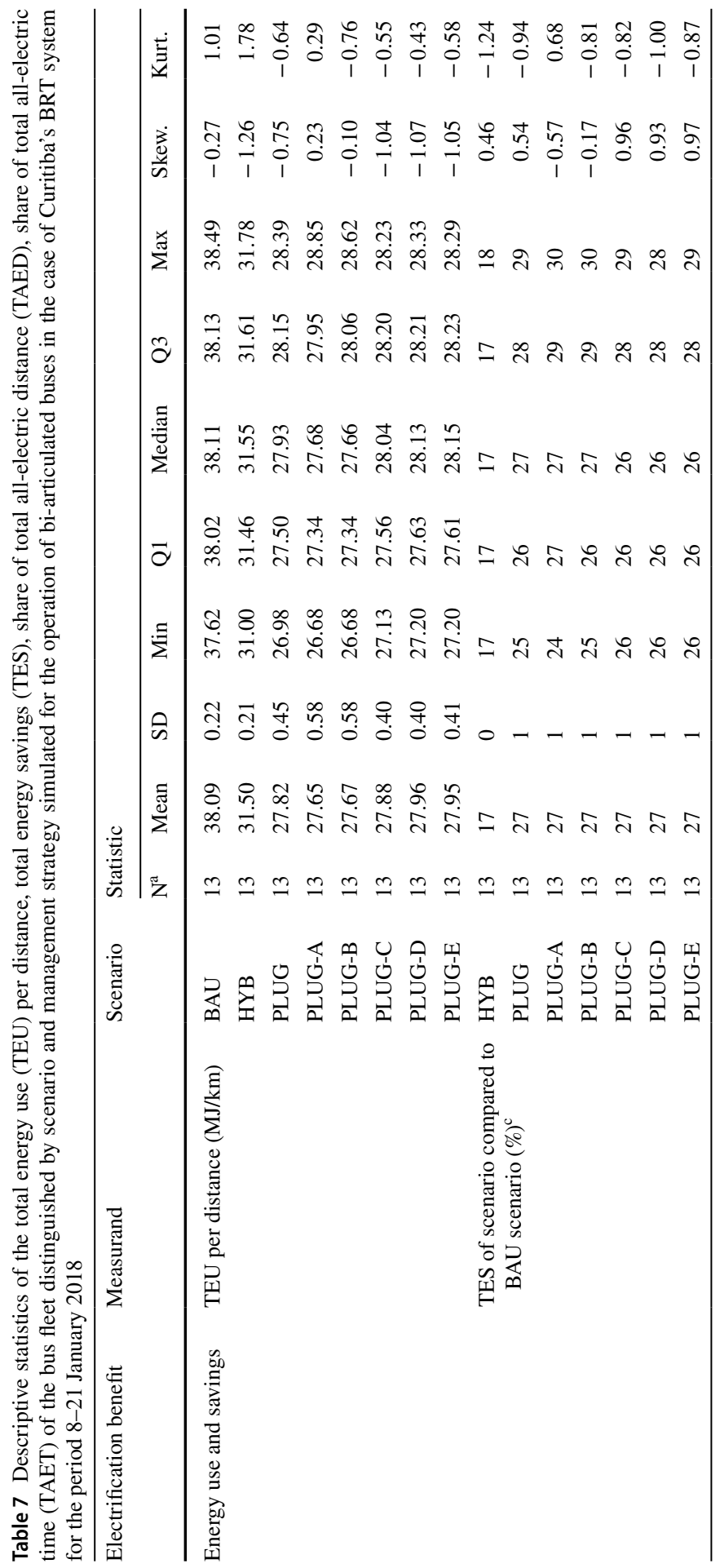




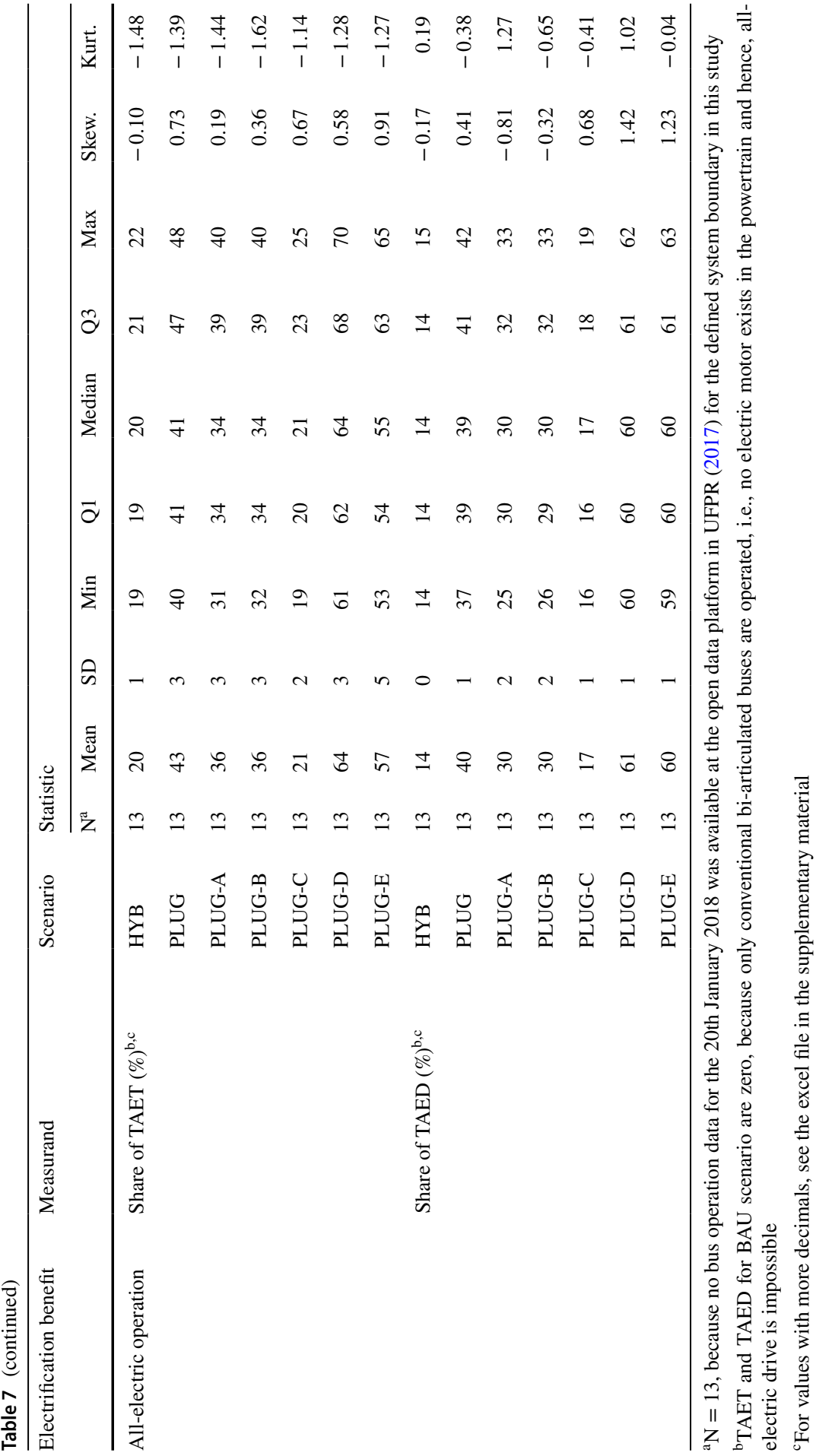


much larger shares of both TAET and TAED compared to the HYB scenarios. The largest share of TAET (64\%) was found in PLUG-D, which fulfils the expectation, since the objective function of strategy D maximises TAET. Additionally, PLUG-D reaches a share of TAED of $61 \%$. This is $1 \%$-point more than PLUG-E that uses strategy E to maximise TAED. This is an interesting finding as it shows that the use of strategy D can simultaneously maximise both TAET and TAED. The finding is presumably caused again by the nature of the greedy algorithm and its optimisation approach for determining local minima rather than a global minimum. Thus, available potentials for TAET and TAED amount to $64 \%$ and $61 \%$, respectively, if the charging schedule and all-electric operation are optimised using strategy D compared to the BAU scenario.

The two simpler strategies A and B, that manage only the charging schedule, achieved shares of TAET and TAED of $30 \%$ and $36 \%$ and are the same for both scenarios PLUG-A and PLUG-B, respectively. The difference between PLUG-A and PLUG-B is visible in the detail that the median value of the share of TAET is $1 \%$-point higher as well as the maximum value of the share of TAED is $1 \%$-point higher for PLUG-B than for PLUG-A, see Table 2. Nevertheless, this is only a marginal indication that strategy $B$ could actually achieve higher TAET and TAED than strategy A.

Comparing both PLUG-A and PLUG-B (TAET: 36\%; TAED: 30\%) to PLUG-D (TAET: 64\%; TAED: 61\%) shows that the absolute percentage differences between the achieved shares of TAET and TAED amount to $28 \%$-points and $31 \%$-points, respectively. Therefore, considerable potentials exist to increase TAET and TAED by using strategy $\mathrm{D}$ for the management of the charging schedule and all-electric operation of the bus fleet rather than using a simple approach such as with strategy A or B. This means that using the stored electricity in the battery in the buses should not be just used when it is available but rather be used when the benefits for allelectric operation are the most. For example, the acceleration of a bus has a higher energy-intensity than steady motion, and therefore, more all-electric operation in terms of time and distance could be achieved by using electricity for the steady motion instead of acceleration.

\section{Conclusions}

In conclusion, the study has made five contributions on the way to find answers to the research question What are the potentials for total energy savings and allelectric operation for a plug-in hybrid-electric bus fleet operated according to selected management strategies?: (I) strategic operational optimisation can be taken up in a real-time optimisation approach; (II) quantification of total energy savings and all-electric operation in different bus deployment and management scenarios; (III) development of a flexible and scalable real-time optimisation model that can be applied in other cities; (IV) demonstration of the use of route-specific and timespecific driving cycle data in the optimisation approach instead of using an average value for the energy use rate of buses; and (V) insights that may be of use to cities 
in similar situations as Curitiba. Given the latter's 'lighthouse' nature this may be desirable and opportune. Specifics are elaborated below tied to the stated contributions from Sect. 2.2, starting with the awaited answers to the research question:

(I) Comparison of five management strategies for a PLUG scenario that focus on multiple objectives

The choice of the strategy strongly influenced the outcome for the potentials for all-electric operation in terms of shares of total all-electric time (TAET) and total all-electric distance (TAED) of the bus fleet. The largest share of TAET was found for strategy $\mathrm{D}$, which is in line with its objective to maximise TAET. Interestingly, strategy D also achieved a 1\%-point higher share of TAED than the actual respective strategy E to maximise TAED. Thus, strategy D simultaneously maximised both TAET and TAED. The comparison of PLUG-D (TAET: 64\%; TAED: 61\%) to PLUG-A and PLUG-B (TAET: 36\%; TAED: $30 \%$ ) showed that the difference between the achieved shares of TAET and TAED amount to $28 \%$-points and $31 \%$-points. These figures indicate considerable potentials to increase all-electric operation when using strategy D instead of simply managing the charging schedule at a charging station according to either the arrival time as in the case of strategy A or affiliation of buses to a bus route as in the case of strategy B. Strategy C, which has the aim to minimise total energy use, performed worse concerning TAET and TAED than strategies A and B. While TAET and TAED could be significantly increased by using a particular strategy, the choice did not influence the potential for total energy savings (TES) of a bus fleet. The respective strategy $\mathrm{C}$ did not perform better than any other strategy concerning TES. Based on the findings, management strategies should be considered to maximise TAET and TAED rather than TES.

(II) Comparison of three electrification scenarios (BAU, HYB, PLUG) for the case of bi-articulated buses in a BRT system

The comparison of the three scenarios showed that total energy savings (TES) increase with an increasing degree of electrification. A potential TES was achieved of $17 \%$ and $27 \%$ in the HYB and PLUG scenarios, respectively, compared to the BAU scenario. This shows that the plug-in hybrid-electric powertrain technology and charging infrastructure could significantly increase the TES advantage from electrification. Based on the example given in Section 5.1, the largest energy saving potential was found from hybridization of the powertrain including use of the regenerative braking system, followed by opportunity charging and overnight charging. Thus, a systematic change of the bus fleet by substituting conventional or hybrid-electric bi-articulated buses by plug-in hybrid-electric bi-articulated buses can save much energy and is independent from any management strategy (A-E).

(III) Development of a flexible and scalable real-time optimisation model

The conceptual framework of the real-time optimisation model was presented, and its application demonstrated by using a small sub-system of Curitiba's BRT system. It was possible to include real-world bus operation data and to simulate and assess different scenarios and management strate- 
gies. The concept is flexible and scalable so that it can be transferred to other bus transport systems to measure available potentials for total energy savings and/or total all-electric operation. Given this flexibility, the realtime optimisation model can be also used to estimate available potentials from the electrification of bus fleets and their management considering a 'retrofit solution'-optimisation. Thus, less-than-ideal designed bus transport systems can be potentially improved, e.g. in systems that have quite arbitrarily selected locations for charging stations.

(IV) Integration of real-world driving cycles into the optimisation model for more dynamic and realistic data-driven decision-making

The integration of the energy use estimation method into the real-time optimisation model made it possible to use real-world driving cycles in the optimisation model. Only in this way, the available potentials of both TAET and TAED could be actually estimated and differences could be compared to the simpler management strategies A and B. Importantly, this would have been impossible if only average values had been used, since the SOC fluctuation would have not been captured and all-electric operation optimisation would have been impossible. Thus, modelling bus transport systems and their optimisation should strive to integrate real-world driving cycles to find (optimal) solutions to more advanced and complex problems as well as to enable a comparison between different levels of complexity, e.g. as the comparison between PLUG-A and B to PLUG-C, D and E.

(V) The C40 network has one member (Curitiba) now with a case study to demonstrate the real-time optimisation approach and to derive insights and recommendations for other cities having a similar status of electrification in their bus transport systems

The findings of the simulations have implications for the city of Curitiba as well as cities having similar conditions in terms of degree of electrification of the bus fleet. The analysis of a small sub-system consisting of a few BRT routes showed that in particular TAET and TAED can strongly vary according to how a plug-in hybrid-electric bus fleet is managed and what the objective is aimed at with the optimisation. Therefore, the gained benefits from electrification in even small pilot projects, as implemented in many cities, such as cities cited in ZeEUS Project (2016), could be potentially optimised if they consider not only bus technology substitutions but also management solutions. By implementing both, the degree of electrification and management strategy are synergised to reduce not only energy use but also maximise TAET and TAED.

The concept of the BRT system is widely used and in particular in developing countries. The findings from the simulations showed that the total energy use (TEU) of the bus fleet can be decreased on average from 38.09 MJ/km for conventional bi-articulated buses to $31.50 \mathrm{MJ} / \mathrm{km}$ when using plug-in hybrid-electric bi-articulated buses. The comparison between the scenarios showed that an absolute decrease by $6.59 \mathrm{MJ} / \mathrm{km}$ for the energy use per distance is potentially achievable. This corresponds to 0.182 litre of fuel (B7) 
equivalent per kilometre (using again the fuel properties from Section 4.3). In Curitiba's BRT system, the operating bus fleet consists of 146 buses that drive together a total mileage of $776037 \mathrm{~km}$ per month (i.e. $177 \mathrm{~km}$ per bus per day for 146 buses and 30 days per month) according to URBS (2017b). A BRT system-wide replacement of all the 146 conventional buses by plug-in hybrid-electric buses would save roughly 1.7 million litre of B7 equivalent per year and hence, 4295 tonnes of GHG emissions when using a conversion factor of $70.10 \mathrm{gCO}_{2} \mathrm{e} / \mathrm{MJ}$ of combusted B7. The conversion factor was retrieved from Dreier et al. (2018). Thus, if the findings could be linearly extrapolated, both significant energy savings and GHG emissions reduction are potentially possible. This shows that the commitment to introduce low-emission buses within the $\mathrm{C} 40$ network is effective concerning energy and climate targets (C40 2015). Considering the rather silent all-electric operation, the commitment further reduces the issue of urban noise emission and thus, can mitigate a severe health thread for humans (EC 2017; WHO 2012).

Lastly, we would like to indicate some suggestions for future work. For example, a techno-economic analysis on the total cost of ownership would be valuable to evaluate whether the application of the real-time optimisation model in the realworld is feasible or not. In this respect, a large-scale simulation could be useful to specify further the computational requirements for the whole city bus fleet. Based on this, a real-world demonstration project could be planned and implemented to review both implementation and operational challenges of the real-time optimisation model when applied in the real-world.

Acknowledgements Open access funding provided by the Royal Institute of Technology. This article was partially developed in the scope of the project Smart city concepts in Curitiba-innovation for sustainable mobility and energy efficiency funded by VINNOVA (Governmental Agency for Innovation Systems) in Sweden. We would like to thank Ingemar Johansson, Stefan Strand, Oscar Hinton and Jonas Andersson at Combitech AB in Sweden for sharing their technical expertise and support. We would also like to thank Professor Dilip Khatiwada at the KTH Royal Institute of Technology in Stockholm, Sweden for his valuable feedback on the first version of this manuscript. Additionally, we thank the three anonymous reviewers for their detailed comments that helped to enhance considerably the quality of this scientific paper.

\section{Compliance with ethical standards}

Conflict of interest No conflict of interest to declare. The research was independently carried out and does neither reflect the opinion of the funding agency nor the involved consulting company.

Open Access This article is licensed under a Creative Commons Attribution 4.0 International License, which permits use, sharing, adaptation, distribution and reproduction in any medium or format, as long as you give appropriate credit to the original author(s) and the source, provide a link to the Creative Commons licence, and indicate if changes were made. The images or other third party material in this article are included in the article's Creative Commons licence, unless indicated otherwise in a credit line to the material. If material is not included in the article's Creative Commons licence and your intended use is not permitted by statutory regulation or exceeds the permitted use, you will need to obtain permission directly from the copyright holder. To view a copy of this licence, visit http://creativecommons.org/licen ses/by/4.0/. 


\section{References}

Borén S, Nurhadi L, Ny H (2016) Preference of electric buses in public transport: conclusions from real life testing in eight swedish municipalities. Int J Env Chem Ecol Geol Geophys Eng 10(3):320-329. https://doi.org/10.5281/zenodo.1112119

Busworld: Bi-articulated 24-metre trolleybus from Solaris coming (2019) https://www.busworld.org/artic les/detail/3571/bi-articulated-24-metre-trolleybus-from-solaris-coming

BYD (2019) Website of BYD Europe, https://bydeurope.com/pdp-bus-model-12

C40 (2015) C40 cities clean bus declaration of intent

C40 (2018) Website of the C40 Cities Climate Leadership Group. http://www.c40.org/cities

Canakci M, van Gerpen JH (2003) Comparison of engine performance and emissions for petroleum diesel fuel, yellow grease, biodiesel and soybean oil biodiesel. Trans ASAE 46:937-944

CBC (2019) Coin-or/Cbc Version 2.10.3. Zenodo. https://zenodo.org/record/3246628\#.Xj8A9MhKhPY

COIN-OR project (2018) Website of Cbc (Coin-or branch and cut) solver. https://www.coin-or.org

Covenant of Mayors (2018) Website of the Covenant of Mayors for Climate \& Energy. https://www.coven antofmayors.eu/en/

Ding H, Hu Z, Song Y (2015) Value of the energy storage system in an electric bus fast charging station. Appl Energy 157:630-639. https://doi.org/10.1016/j.apenergy.2015.01.058

Drake N (2018) Best cloud computing services of 2018. https://www.techradar.com/news/best-cloud -computing-service

Dreier D (2015) Assessing the potential of fuel saving and emissions reduction of the bus rapid transit system in Curitiba, Brazil. http://www.diva-portal.org/smash/record.jsf?pid=diva2\%3A866 $911 \&$ dswid $=307$

Dreier D, Silveira S, Khatiwada D, Fonseca KVO, Nieweglowski R, Schepanski R (2018) Well-to-Wheel analysis of fossil energy use and greenhouse gas emissions for conventional, hybrid-electric and plug-in hybrid-electric city buses in the BRT system in Curitiba, Brazil. Transp Res Part D Transp Env 58:122-138. https://doi.org/10.1016/j.trd.2017.10.015

Dreier D, Silveira S, Khatiwada D, Fonseca KVO, Nieweglowski R, Schepanski R (2019) The influence of passenger load, driving cycle, fuel price and different types of buses on the cost of transport service in the BRT system in Curitiba, Brazil. Transportation 46(6):2195-2242. https://doi. org/10.1007/s11116-018-9925-0

Du J, Chen J, Song Z, Gao M, Ouyang M (2017) Design method of a power management strategy for variable battery capacities range-extended electric vehicles to improve energy efficiency and costeffectiveness. Energy 121:32-42. https://doi.org/10.1016/j.energy.2016.12.120

EC: European Commission (EC) (2017) Noise, a hidden health threat. https://ec.europa.eu/environment/ efe/themes/urban-noise-and-health/noise-hidden-health-threat_en

EC: European Commission (EC) (2018) Cities, https://ec.europa.eu/clima/policies/international/paris _protocol/cities_en

Gao Z, Lin Z, Laclair TJ, Liu C, Li J, Birky AK, Ward J (2017) Battery capacity and recharging needs for electric buses in city transit service. Energy 122:588-600. https://doi.org/10.1016/j.energy.2017.01.101

Gillespie T (1992) Fundamentals of vehicle dynamics. SAE, Warrendale, PA

Global BRT Data (2015) Fuel economy, biarticulated buses. http://brtdata.org/indicators/systems/fuel_econo my_bi-articulated_buses

Hammer $\varnothing$, Harper DAT, Ryan PD (2001) PAST: paleontological statistics software package for education and data analysis. Palaeontol Electron 1:9

He J, Yang H, Tang T, Huang H (2018) An optimal charging station location model with the consideration of electric vehicle's driving range. Transp Res Part C 86:641-654. https://doi.org/10.1016/j. trc.2017.11.026

Hensher DA, Golob TF (2008) Bus rapid transit systems: a comparative assessment. Transportation 35:501518. https://doi.org/10.1007/s11116-008-9163-y

Hensher DA, Li Z (2012a) Ridership drivers of bus rapid transit systems. Transportation 39:1209-1221. https ://doi.org/10.1007/s11116-012-9392-y

Hensher DA, Li Z (2012b) Erratum to Ridership drivers of bus rapid transit systems (Transportation, 10.1007/ s11116-012-9392-y). Transportation 39:1223-1224. https://doi.org/10.1007/s11116-012-9416-7

Hensher DA, Mulley C (2015) Modal image: candidate drivers of preference differences for BRT and LRT. Transportation 42:7-23. https://doi.org/10.1007/s11116-014-9516-7 
Heres DR, Jack D, Salon D (2014) Do public transport investments promote urban economic development? Evidence from bus rapid transit in Bogotá, Colombia. Transportation. 41:57-74. https://doi. org/10.1007/s11116-013-9471-8

Hõimoja H, Rufer A, Dziechciaruk G, Vezzini A (2012) An ultrafast EV charging station demonstrator. In: SPEEDAM 2012-21st international symposium on power electronics, electrical drives, automation and motion, pp 1390-1395. https://doi.org/10.1109/SPEEDAM.2012.6264617

IEA (2016) International Energy Agency (IEA). Key world energy statistics 2016. https://doi.org/10.1787/ key_energ_stat-2016-en

ISO (1975) International Organization for Standardization (ISO) 2533: Standard Atmosphere

Jurca FN, Ruba M, Martis C (2015) Analysis of permanent magnet synchronous machine for integrated starter-alternator-booster applications. In: 2015 international conference on electrical drives and power electronics (EDPE), pp 21-23. https://doi.org/10.1109/EDPE.2015.7325305

Kunith A, Mendelevitch R, Goehlich D (2017) Electrification of a city bus network - an optimization model for cost-effective placing of charging infrastructure and battery sizing of fast-charging electric bus systems. Int J Sustain Transp 11:707-720. https://doi.org/10.1080/15568318.2017.1310962

Liu Z, Song Z (2017) Robust planning of dynamic wireless charging infrastructure for battery electric buses. Transp Res Part C 83:77-103. https://doi.org/10.1016/j.trc.2017.07.013

Mahmoud M, Garnett R, Ferguson M, Kanaroglou P (2016) Electric buses: a review of alternative powertrains. Renew Sustain Energy Rev 62:673-684. https://doi.org/10.1016/j.rser.2016.05.019

McKinney W (2010) Data structures for statistical computing in Python. In: Presented at the Proceedings of the 9th Python in Science Conference

Millo F, Rolando L, Fuso R (2014) Real world operation of a complex plug-in hybrid electric vehicle: analysis of its CO2 emissions and operating costs. Energies. 7:4554-4570. https://doi.org/10.3390/en707 4554

Mitchell S, O’Sullivan M, Dunning I (2011) PuLP: a linear programming toolkit for python

Nylund N, Erkkilä K, Hartikka T (2007) Fuel consumption and exhaust emissions of urban buses. Performance of the new diesel technology. In: VTT Tiedotteita Research Notes 2373. VTT, Espoo, Finland

Olsson O, Grauers A, Pettersson S (2016) Method to analyze cost effectiveness of different electric bus systems. In: EVS29 symposium, pp 1-12

OpenStreetMap contributors: OpenStreetMap (2019) https://www.openstreetmap.org/copyright

Paul T, Yamada H (2014) Operation and charging scheduling of electric buses in a city bus route network. In: 2014 IEEE 17th international conference on intelligent transportation systems (ITSC), pp 2780-2786

Perrotta D, Ribeiro B, Rossetti RJF, Afonso JL (2012) On the potential of regenerative braking of electric buses as a function of their itinerary. In: Procedia—social and behavioral sciences, pp 1156-1167

Python Software Foundation (2018) Python Language Reference, version 3.6.4. https://docs.python.org/3

Qin N, Gusrialdi A, Brooker RP, T-raissi A (2016) Numerical analysis of electric bus fast charging strategies for demand charge reduction. Transp Res Part A 94:386-396. https://doi.org/10.1016/j.tra.2016.09.014

Qlik (2019) Data analytics platformlQlik Sense. https://www.qlik.com/us/products/qlik-sense

Rahman M, Wirasinghe SC, Kattan L (2018) Analysis of bus travel time distributions for varying horizons and real-time applications. Transp Res Part C 86:453-466. https://doi.org/10.1016/j.trc.2017.11.023

Ranta M, Karvonen V, Potter JJ, Pasonen R, Pursiheimo E, Halmeaho T, Ponomarev P, Pihlatie M (2016) Method including power grid model and route simulation to aid planning and operation of an electric bus fleet. https://doi.org/10.1109/VPPC.2016.7791724

Rogge M, Wollny S, Sauer DU (2015) Fast charging battery buses for the electrification of urban public transport - a feasibility study focusing on charging infrastructure and energy storage requirements. Energies 2015:4587-4606. https://doi.org/10.3390/en8054587

Rosenkranz C (2003) Deep cycle batteries for plug-in hybrid application. In: Presented at EVS-20 plug-in hybrid workshop, Monaco

Sebastiani MT, Lüders R, Fonseca KVO (2016) Evaluating electric bus operation for a real-world BRT public transportation using simulation optimization. IEEE Trans Intell Transp Syst 17:2777-2786. https:// doi.org/10.1109/TITS.2016.2525800

Siemens (2018) Charging systems for ebuses. https:/www.siemens.com/global/en/home/products/mobility/ road-solutions/electromobility/ebus-charging.html

Spielman DA, Teng S-H (2004) Smoothed analysis of algorithms: why the simplex algorithm usually takes polynomial time. J ACM 51:385-463. https://doi.org/10.1145/990308.990310

Stokes A, Poger L (2013) Electric drive buses. Adv Energy

Suzdaleva E, Nagy I (2018) An online estimation of driving style using data-dependent pointer model. Transp Res Part C 86:23-36. https://doi.org/10.1016/j.trc.2017.11.001 
Tao S, Corcoran J, Rowe F, Hickman M (2018) To travel or not to travel: ' Weather' is the question. Modelling the effect of local weather conditions on bus ridership. Transp Res Part C Emerg Technol 86:147167. https://doi.org/10.1016/j.trc.2017.11.005

UFPR (2017) Open data online platform of the UFPR — Federal University of Paraná, bus transport system data sets. http://dadosabertos.c3sl.ufpr.br/curitibaurbs/

UNFCCC (2015) Adoptation of the Paris Agreement FCCC/CP/2015/L.9/Rev.1

United Nations: United Nations (UN) (2014) World urbanization prospects: the 2014 revision, highlights (ST/ESA/SER.A/352). In: UN Department of Economic and Social Affairs

URBACT (2018) Website of the URBACT programme. http://urbact.eu/

URBS (2015) Comparative evaluation of new technologies for operation in the collective transportation of Curitiba (In Portuguese: Avaliação Comparativa de Novas Tecnologias para Operação no Transporte Coletivo de Curitiba). In: URBS-Urbanization of Curitiba S/A, Curitiba, Brazil

URBS (2017a) Website of URBS. www.urbs.curitiba.pr.gov.br

URBS (2017b) Composition of cost per kilometer by type of vehicle (In Portuguese: Composição do custo/ $\mathrm{km}$ por tipo de veículo)

van der Walt S, Colbert SC, Varoquaux G (2011) The NumPy Array: a structure for efficient numerical computation. Comput Sci Eng 13:22-30. https://doi.org/10.1109/MCSE.2011.37

van Kooten Niekerk ME, van den Akker JM, Hoogeveen JA (2017) Scheduling electric vehicles. Public Transp 9:155-176. https://doi.org/10.1007/s12469-017-0164-0

Volvo Bus Corporation (2011) Volvo Bus telematics to reduce cost. https://www.volvobuses.com/en-en/ news/2011/oct/news-111097.html

Volvo Bus Corporation (2016a) Start of testing an electric hybrid bus by Volvo in Latin America (In Portuguese). http://www.mobilidadevolvo.com.br/onibus-hibrido-eletrico-volvo-em-curitiba/

Volvo Bus Corporation (2016b) Website of Volvo Buses: Volvo 7900 Electric Hybrid. In: Technical specifications

Volvo Bus Corporation (2018a) Website of Volvo Buses: Volvo 7900 Hybrid Articulated. https://www.volvo buses.de/de-de/our-offering/buses/volvo-7900-hybrid/specifications.html

Volvo Bus Corporation (2018b) Technical specifications of Volvo B340M Articulated and Bi-articulated. https://www.volvobuses.com.br/pt-br/our-offering/buses/b340m-articulado-biarticulado/specifications. html

Volvo Group UK (2017) 7900 Electric Hybrid UK Brochure, Wedgnock Lane, Warwick CV34 5YA

Wang H, Zhang X, Ouyang M (2015) Energy consumption of electric vehicles based on real-world driving patterns: a case study of Beijing. Appl Energy 157:710-719. https://doi.org/10.1016/j.apene rgy.2015.05.057

Wang Y, Huang Y, Xu J, Barclay N (2017) Optimal recharging scheduling for urban electric buses: a case study in Davis. Transp Res Part E 100:115-132. https://doi.org/10.1016/j.tre.2017.01.001

WHO (2012) World Health Organization (WHO). Methodological guidance for estimating the burden of disease from environmental noise

Wikner E, Thiringer T (2018) Extending battery lifetime by avoiding high SOC. Appl Sci 8:1825. https://doi. org/10.3390/app8101825

Wright L, Hook W (2007) Bus rapid transit planning guide. Institute for Transportation \& Development Policy, New York

Xu Y, Gbologah FE, Lee D-Y, Liu H, Rodgers MO, Guensler RL (2015) Assessment of alternative fuel and powertrain transit bus options using real-world operations data: Life-cycle fuel and emissions modeling. Appl Energy 154:143-159. https://doi.org/10.1016/j.apenergy.2015.04.112

Xylia M, Leduc S, Patrizio P, Kraxner F, Silveira S (2017) Locating charging infrastructure for electric buses in Stockholm. Transp Res Part C 78:183-200. https://doi.org/10.1016/j.trc.2017.03.005

Yay E, Martínez N, Antonio J, Ramírez O (2016) Detecting the adherence of driving rules in an energyefficient, safe and adaptive driving system. Expert Syst Appl 47:58-70. https://doi.org/10.1016/j. eswa.2015.10.044

Yu H, Tarsitano D, Hu X, Cheli F (2016a) Real time energy management strategy for a fast charging electric urban bus powered by hybrid energy storage system. Energy 112:322-331. https://doi.org/10.1016/j. energy.2016.06.084

Yu Q, Li T, Li H (2016b) Improving urban bus emission and fuel consumption modeling by incorporating passenger load factor for real world driving. Appl Energy 161:101-111. https://doi.org/10.1016/j.apene rgy.2015.09.096

ZeEUS Project (2016) ZeEUS eBus Report An overview of electric buses in Europe. https://zeeus.eu/uploa ds/publications/documents/zeeus-ebus-report-internet.pdf 
Zhang M (2009) Bus versus rail meta-analysis of cost characteristics, carrying capacities, and land use impacts. Transp Res Record 2110:87-95. https://doi.org/10.3141/2110-11

Zhang S, Wu Y, Liu H, Huang R, Un P, Zhou Y, Fu L, Hao J (2014) Real-world fuel consumption and $\mathrm{CO}_{2}$ (carbon dioxide) emissions by driving conditions for light-duty passenger vehicles in China. Energy 69:247-257. https://doi.org/10.1016/j.energy.2014.02.103

Publisher's Note Springer Nature remains neutral with regard to jurisdictional claims in published maps and institutional affiliations.

\section{Affiliations}

\section{Dennis Dreier ${ }^{1}\left([) \cdot\right.$ Björn Rudin ${ }^{2} \oplus \cdot$ Mark Howells ${ }^{3,4} \oplus$}

$\triangle$ Dennis Dreier

ddreier@kth.se

Mark Howells

M.I.Howells@lboro.ac.uk

1 Department of Energy Technology, KTH Royal Institute of Technology, Brinellvägen 68, 10044 Stockholm, Sweden

2 Combitech AB, Linköping, Sweden

3 Geography and Environment, School of Social Sciences, Loughborough University, Loughborough, UK

4 Center for Environmental Policy, Imperial College London, London, UK 